\title{
Evaluation of the performance of existing mathematical models predicting enteric methane emissions from ruminants: animal categories and dietary mitigation strategies
}

Article

Accepted Version

Creative Commons: Attribution-Noncommercial-No Derivative Works 4.0

Benaouda, M., Martin, C., Li, X., Kebreab, E., Hristov, A. N., Yu, Z., Yáñez-Ruiz, D. R., Reynolds, C. K., Crompton, L. A., Dijkstra, J., Bannink, A., Schwarm, A., Kreuzer, M., McGee, M., Lund, P., Hellwing, A. L. F., Weisbjerg, M. R., Moate, P. J., Bayat, A. R., Shingfield, K. J., Peiren, N. and Eugène, M. (2019) Evaluation of the performance of existing mathematical models predicting enteric methane emissions from ruminants: animal categories and dietary mitigation strategies. Animal Feed Science and Technology, 225. 114207. ISSN 0377-8401 doi: https://doi.org/10.1016/j.anifeedsci.2019.114207 Available at https://centaur.reading.ac.uk/84631/

It is advisable to refer to the publisher's version if you intend to cite from the work. See Guidance on citing.

To link to this article DOI: http://dx.doi.org/10.1016/j.anifeedsci.2019.114207

Publisher: Elsevier 
All outputs in CentAUR are protected by Intellectual Property Rights law, including copyright law. Copyright and IPR is retained by the creators or other copyright holders. Terms and conditions for use of this material are defined in the End User Agreement.

\section{www.reading.ac.uk/centaur}

\section{CentAUR}

Central Archive at the University of Reading

Reading's research outputs online 
1 Evaluation of the performance of existing mathematical models predicting enteric methane emissions from ruminants: animal categories and dietary mitigation strategies

Mohammed Benaouda ${ }^{\mathrm{a}, \mathrm{b}}$, Cécile Martin ${ }^{\mathrm{a}, \mathrm{b}}$, Xinran Li ${ }^{\mathrm{a}, \mathrm{b}}$, Ermias Kebreab ${ }^{\mathrm{c}}$, Alexander N. Hristov $^{\mathrm{d}}$, Zhongtang Yu ${ }^{\mathrm{e}}$, David R. Yáñez-Ruiz ${ }^{\mathrm{f}}$, Christopher K. Reynolds ${ }^{\mathrm{g}}$, Les A. Crompton ${ }^{\mathrm{g}}$, Jan Dijkstra ${ }^{\mathrm{h}}$, André Bannink ${ }^{\mathrm{i}}$, Angela Schwarm ${ }^{\mathrm{j}, 2}$, Michael Kreuzer ${ }^{\mathrm{j}}$, Mark McGee ${ }^{\mathrm{k}}$, Peter Lund $^{1}$, Anne L. F. Hellwing ${ }^{1}$, Martin R. Weisbjerg ${ }^{1}$, Peter J. Moate ${ }^{\mathrm{m}}$, Ali R. Bayat ${ }^{\mathrm{n}}$, Kevin J. Shingfield $\dagger^{\mathrm{n}}$, Nico Peiren ${ }^{\mathrm{o}}$ and Maguy Eugène ${ }^{\mathrm{a}, \mathrm{b}, 1}$.

${ }^{a}$ INRA, UMR1213 Herbivores, F-63122 Saint-Genès-Champanelle, France; ${ }^{\mathrm{b}}$ Clermont Université, VetAgro Sup, UMR1213 Herbivores, BP 10448, F-63000, Clermont-Ferrand,

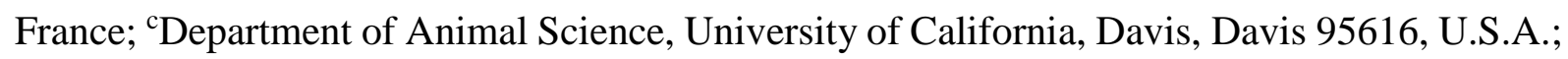
${ }^{\mathrm{d}}$ Department of Animal Science, The Pennsylvania State University, University Park 16802,

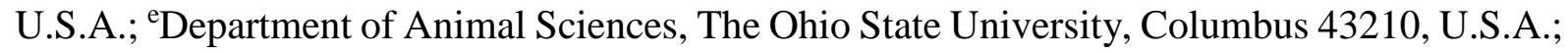
${ }^{\mathrm{f}}$ Estacion Experimental del Zaidin, CSIC, Granada, Spain; ${ }^{\mathrm{g}}$ School of Agriculture, Policy, \& Development, University of Reading, Reading, RG6 6AR, UK; ${ }^{\mathrm{h}}$ Animal Nutrition Group, Wageningen University \& Research, Wageningen, the Netherlands; ${ }^{i}$ Wageningen Livestock Research, Wageningen University \& Research, Wageningen, The Netherlands; ${ }^{j}$ ETH Zurich, Institute of Agricultural Sciences, 8092 Zurich, Switzerland; ${ }^{k}$ Teagasc, Animal and Grassland Research and Innovation Centre, Grange, Dunsany, Co. Meath, Ireland; ${ }^{1}$ Department of Animal Science, AU Foulum, Aarhus University, Blichers Allé 20, DK 8830 Tjele, Denmark; ${ }^{\mathrm{m}}$ Agriculture Victoria, Ellinbank Centre, 1301 Hazeldean Road, Ellinbank, Victoria, 3820, Australia; ${ }^{n}$ Milk Production, Production Systems, LUKE Natural Resources Institute Finland, 31600 Jokioinen, Finland; ${ }^{\circ}$ Animal Sciences Unit, Flanders research institute for agriculture, fisheries and food, 9090 Melle, Belgium.

\section{${ }^{1}$ Corresponding author}

Maguy Eugène: maguy.eugene@inra.fr. 
${ }^{2}$ Present address: Department of Animal and Aquacultural Sciences, Norwegian University of Life Sciences, PO Box 5003, 1432 Ås, Norway

\section{Abstract}

The objective of this study was to evaluate the performance of existing models predicting enteric methane $\left(\mathrm{CH}_{4}\right)$ emissions, using a large database (3183 individual data from 103 in vivo studies on dairy and beef cattle, sheep and goats fed diets from different countries). The impacts of dietary strategies to reduce $\mathrm{CH}_{4}$ emissions, and of diet quality (described by organic matter digestibility (dOM) and neutral-detergent fiber digestibility (dNDF)) on model performance were assessed by animal category. The models were first assessed based on the root mean square prediction error (RMSPE) to standard deviation of observed values ratio (RSR) to account for differences in data between models and then on the RMSPE. For dairy cattle, the $\mathrm{CH}_{4}$ (g/d) predicting model based on feeding level (dry matter intake (DMI)/body weight (BW)), energy digestibility (dGE) and ether extract (EE) had the smallest RSR (0.66) for all diets, as well as for the high-EE diets $(\mathrm{RSR}=0.73)$. For mitigation strategies based on lowering NDF or improving dOM, the same model ( $\mathrm{RSR}=0.48$ to 0.60$)$ and the model using DMI and neutraland acid-detergent fiber intakes ( $R S R=0.53$ ) had the smallest RSR, respectively. For diets with high starch (STA), the model based on nitrogen, ADF and STA intake presented the smallest RSR (0.84). For beef cattle, all evaluated models performed moderately compared with the models of dairy cattle. The smallest RSR (0.83) was obtained using variables of energy intake, BW, forage content and dietary fat, and also for the high-EE and the low-NDF diets (RSR = 0.84 to 0.86 ). The IPCC Tier 2 models performed better when dietary STA, dOM or dNDF were high. For sheep and goats, the smallest RSR was observed from a model for sheep based on dGE intake $(\mathrm{RSR}=0.61)$. Both IPCC models had low predictive ability when dietary EE, $\mathrm{NDF}, \mathrm{dOM}$ and $\mathrm{dNDF}$ varied (RSR $=0.57$ to 1.31 in dairy, and 0.65 to 1.24 in beef cattle). The performance of models depends mostly on explanatory variables and not on the type of data 
51 (individual vs. treatment means) used in their development or evaluation. Some empirical models give satisfactory prediction error compared with the error associated with measurement methods. For better prediction, models should include feed intake, digestibility and additional information on dietary concentrations of EE and structural and nonstructural carbohydrates to account for different dietary mitigating strategies.

\section{Keywords}

Model evaluation; methane emission; ruminant; dietary strategy

\section{Abbreviations}

ADF, acid-detergent fiber; ADFI, ADF intake; AU, Australia; BW, body weight; CCC, concordance correlation coefficient; $\mathrm{CH}_{4}$, enteric methane; $\mathrm{CV}$, coefficient of variation; $\mathrm{dGE}$, digestibility of GE; DM, dry matter; DMI, DM intake; dNDF, digestibility of neutral-detergent fiber; dOM, digestibility of organic matter; ECT, error in central tendency; ED, error due to the disturbance; EE, ether extract; ER, error due to the regression; EUR, Europe; FA, fatty acids; FPCM, fat and protein corrected milk; GE, gross energy; GEI, GE intake; GHG, greenhouse gas; IPCC, Intergovernmental Panel on Climate Change; MSPE, mean square prediction error; NDF, neutral-detergent fiber; NDFI, NDF intake; OM, organic matter; RMSPE, root MSPE; RSR, RMSPE to standard deviation of observed values ratio; $\mathrm{SF}_{6}$, Sulphur hexafluoride tracer; STA, starch; US, United States of America; Ym, percentage of GE converted into $\mathrm{CH}_{4}$;

\section{Introduction}

Accurate estimation of enteric methane $\left(\mathrm{CH}_{4}\right)$ emissions from ruminants is important for national greenhouse gas (GHG) inventories and for assessing dietary mitigating strategies. In many countries, the IPCC (2006) Tier 1 or Tier 2 methodologies are used to report their national inventories of GHG emissions. The IPCC Tier 2 model, although more detailed than Tier 1, relies on gross energy intake (GEI) which can lead to inaccuracy in predicting $\mathrm{CH}_{4}$ emissions for diets of different nutrient composition (Ellis et al., 2010). The determination of $\mathrm{CH}_{4}$ 
emissions from individual animals requires specialized equipment (Hammond et al., 2016) and expensive methodologies (Kebreab et al., 2006). Many empirical models have been developed for specific ruminant categories to estimate $\mathrm{CH}_{4}$ emissions from dairy cattle (Charmley et al., 2016; Niu et al., 2018), beef cattle (Ellis et al., 2009; Cottle and Eckard, 2018) and small ruminants (Patra et al., 2016; Patra and Lalhriatpuii, 2016) or for all ruminants (Blaxter and Clapperton, 1965; IPCC, 1997 and 2006; Sauvant et al., 2011; Ramin and Huhtanen, 2013).

Most prediction models are based on feed intake (dry matter intake (DMI) or GEI). However, these models do not adequately account for the effect of other dietary factors such as lipid supplementation (Bannink et al., 2006), neutral detergent fiber (NDF) content, organic matter digestibility (dOM) (Archimède et al., 2011; Appuhamy et al., 2016), content of starch (STA) and sugars (Hindrichsen et al., 2005) and the presence of plant secondary compounds (Jayanegara et al., 2012). Consequently, alternative models that take into account feed properties and animal characteristics to improve prediction of $\mathrm{CH}_{4}$ emissions under different nutritional mitigation strategies have been proposed. Some models can be applied across all ruminant categories (Blaxter and Clapperton, 1965; IPCC, 2006; Ramin and Huhtanen, 2013; Bell et al., 2016) whereas others are specific to one ruminant category (Charmley et al., 2016; Escobar-Bahamondes et al., 2017a; Cottle and Eckard, 2018).

There is global interest in the use of nutrition and feeding management to decrease $\mathrm{CH}_{4}$ emissions from ruminants (Knapp et al., 2014). Consequently, if the national inventory calculations are based on empirical models, these should be assessed for their reliability under different nutritional mitigation strategies and different production conditions. The objectives of this study were to evaluate the performance of existing models using a large database of individual records for specific 1) ruminant categories (dairy cattle, beef cattle, sheep or goats) and 2) nutritional strategies that mitigate $\mathrm{CH}_{4}$ emissions (lipid and STA supplementation, low NDF content in the diet, or enhanced diet digestibility). 


\subsection{Database}

103

A database of 3183 individual observations from the GLOBAL NETWORK project (https://globalresearchalliance.org/research/livestock/collaborative-activities/global-researchproject/) was used to evaluate the performance of models that predict $\mathrm{CH}_{4}$ emissions from ruminants. This individual database (Table 1) included 103 studies from three regions: Europe (EUR; 2707 observations from 92 studies), United States of America (US; 198 observations from 5 studies) and Australia (AU; 278 observations from 6 studies). Enteric $\mathrm{CH}_{4}$ emissions included in the present database were measured using respiration chambers (65\% of data), $\mathrm{SF}_{6}$ tracer technique (30\%) and automated head chamber (GreenFeed ${ }^{\mathrm{TM}}, \mathrm{C}-$ Lock Inc., Rapid City,

111 SD, US; 5\%), on different animal categories (dairy cattle, 67\%; beef cattle, 18\%; sheep, 13\%;

112 goat, 2\%), using various experimental designs (randomized block design (average adaptation duration 47 days), latin square design (average adaptation duration 19 days), change-over or

114 switch-back design (average adaptation duration 15 days)).

\section{Data pre-processing}

116 Data pre-processing was performed, because the collected data were sometimes incomplete

117 (missing values or variables of interest), inconsistent (different names or units for the same 118 variable) and noisy (containing errors or outliers). We corrected the inconsistent data by using

119 the same name and unit across all studies. Outliers in the database were screened as described

120 by Niu et al. (2018). No data on gross energy content and chemical composition of the diets

121 were available for the AU dairy cattle data. All data on dietary composition for beef cattle, 122 sheep and goat subsets were from EUR. Finally, the dietary treatments were classified according to the purpose of each study into four $\mathrm{CH}_{4}$ mitigation strategies (A to D), as classified 
content of the diet); (B) low fiber content in the diet (NDF content of the diet); (C) high STA

126 content in the diet, and (D) high-quality diet (in terms of dOM and dNDF).

\subsection{Selection of Models}

128 To select the models, we used web search online databases (Science Direct, Web of Science)

129 for articles written in English and published from 2000 to 2017 using the following key words:

130 "methane", "in vivo", "prediction", "model" (or "equation") and "ruminant" (or "cattle" or

131 "dairy" or "beef" or "sheep" or "goat"). Only models with predictor variables or required

132 information that were available in our database were selected (Table 2). Therefore, due to the

133 lack of information, the models of $\mathrm{CH}_{4}$ emissions from ruminants fed plants rich of secondary

134 compounds were not evaluated. Some models were specific to one ruminant category (e.g.,

135 Charmley et al. (2016)), whereas others were applicable to more than one category. In addition

136 to the IPCC models, the models from Sauvant et al. (2011) were evaluated with data from all

137 ruminant categories. The models from Ramin and Huhtanen (2013) were evaluated with dairy

138 and beef cattle and sheep. The models containing variables associated with dietary lipid content

139 were used to evaluate their predictive ability for lipid supplementation mitigation strategy. The

140 models that take into account dietary NDF, dOM or dNDF were used to evaluate their ability

141 to predict $\mathrm{CH}_{4}$ when ruminants are fed a high-quality diet (Low NDF content or high dOM and

142 dNDF). The models that use STA content or dietary concentrate content as variables, were

143 tested for their predictive ability when a large level of STA was used to reduce $\mathrm{CH}_{4}$ emissions.

144 The published models were grouped based on the region of data origin (EUR, US or AU) and

145 the type of data used in their development (individual data or treatment means). All models

146 were used in their original version except one model from Nielsen et al. (2013) based on DMI,

147 EE and NDF contents, where we used the modified version of Appuhamy et al. (2016). Some

148 models are based on fatty acids (FA) instead of ether extract content, so the total FA content in

149 the diet was estimated using the adapted model of Giger-Reverdin et al. (2003): 
$\% \mathrm{FA} / \mathrm{EE}=100-\left(32-5.86 \times \mathrm{EE}+0.261 \times \mathrm{EE}^{2}+0.287 \times\right.$ forage $)$

151 The unit of EE and forage proportion used in this equation is \% DM.

152 The $\mathrm{CH}_{4}$ unit used in the present evaluation is $\mathrm{g} / \mathrm{d}$; hence, when original equations used $\mathrm{MJ} / \mathrm{d}$, 153 a conversion factor (55.65 $\mathrm{kJ}$ per $\mathrm{g}$ of $\mathrm{CH}_{4}$; Brouwer 1965) was used. When the equation was 154 reported in $\mathrm{L} / \mathrm{d}$, it was converted to $\mathrm{g} / \mathrm{d}$ using the molar density of $\mathrm{CH}_{4}(0.714 \mathrm{~g} / \mathrm{L})$.

\section{Choices of data for model evaluation}

156 Before model evaluation, data were checked to ensure there was no overlap between model 157 development and validation sets. Consequently, data originally used in model development by 158 the respective groups of researchers were excluded before evaluation of that particular model.

159 For example, the 154 observations used by Charmley et al. (2016) to develop their models were 160 removed before evaluating the performance of models from Charmley et al. (2016). For the

161 same reason, the models developed by Niu et al. (2018) were not tested, as these models were derived from a large share of the database used in the present evaluation.

163 Next, we selected the data based on each model's specifications with respect to ruminant 164 category and $\mathrm{CH}_{4}$ mitigation strategy. For instance, ruminant category-specific models were 165 evaluated only using the data from the respective ruminant category, whereas generic models 166 were evaluated first using the data from each ruminant category separately and then using the 167 data of all ruminant categories.

168 The evaluation of models by $\mathrm{CH}_{4}$ mitigation strategies was carried out within each ruminant 169 category (dairy cattle, beef cattle, sheep and goats). Using the dietary content of EE, NDF and 170 STA values, the database was separated into two subsets for each strategy to assess, respectively, 171 the mitigation strategies of lipid supplementation, enhancement of diet quality by lowering 172 dietary fiber and the use of the high-STA diets. In addition, the performance of models was 173 assessed by variation in the diet quality (variations in $\mathrm{dOM}$ and in $\mathrm{dNDF}$ ). The separation into 174 two subsets for lipid supplementation was set by mean of EE content. For the mitigation strategy 
175 based on the use of STA, the two subsets were obtained from subtracting the standard deviation

176 from the mean of STA content. For NDF content in dairy cattle diets, the fixed threshold of 350

$177 \mathrm{~g} / \mathrm{kg}$ DM was used, due to the non-normal distribution of NDF data for this animal category.

178 Consequently, given the distribution of data the resulting thresholds were $39.3 \mathrm{~g}$ of EE/kg DM,

$179350 \mathrm{~g}$ of NDF/kg DM, and $101 \mathrm{~g}$ of STA/kg DM, for dairy cattle and $40 \mathrm{~g}$ of EE/kg DM, $338 \mathrm{~g}$

180 of $\mathrm{NDF} / \mathrm{kg} \mathrm{DM}$ and $110 \mathrm{~g}$ of STA/kg DM for beef cattle. Within each strategy, the datasets

181 obtained were then qualified as low or high when dietary contents were lower or higher than

182 those thresholds, respectively. The existing models were originally developed from either

183 individual animal or treatment mean datasets. To test the effect of data type (individual vs.

184 means) on the performance of models, our individual database was transformed into a "means"

185 database by obtaining arithmetic means of the individual observations within the same

186 treatment and within each experiment. Four individual and four mean models with the smallest

187 RSR predicting $\mathrm{CH}_{4}$ emissions from dairy cattle were evaluated using individual and mean

188 databases.

\subsection{Criteria for model evaluation}

190 The $\mathrm{CH}_{4}$ prediction models were evaluated using the following criteria. The prediction model

191 associated with the lowest root mean square prediction error (RMSPE) to standard deviation of

192 observed values ratio (RSR) and the lowest RMSPE is considered the best performing:

193 Mean Square Prediction Error

194 The mean square prediction error (MSPE) was calculated according to Bibby and Toutenburg 195 (1977):

196

$$
M S P E=\frac{1}{n} \sum_{i=1}^{n}\left(O_{i}-P_{i}\right)^{2}
$$


197 Where $\mathrm{n}$ is the number of observations, $\boldsymbol{O}_{\boldsymbol{i}}$ is the $\mathrm{i}^{\text {th }}$ observed value and $\boldsymbol{P}_{\boldsymbol{i}}$ is the $\mathrm{i}^{\text {th }}$ predicted

198 value. Usually, square root of the MSPE (RMSPE) is used to evaluate model prediction because

199 it has the same unit as the observed values:

$$
R M S P E=\sqrt{\frac{1}{n} \sum_{i=1}^{n}\left(O_{i}-P_{i}\right)^{2}}
$$

In the present research, RMSPE was also expressed as a percentage of mean observed $\mathrm{CH}_{4}$ mitigation strategies:

$$
R M S P E \%=\frac{\frac{1}{n} \sqrt{\sum_{i=1}^{n}\left(O_{i}-P_{i}\right)^{2}}}{\frac{1}{n} \sum_{i=1}^{n} O_{i}} \times 100
$$

A smaller value of RMSPE and RMSPE\% indicates better performance of model prediction. of precision) or mean bias, error due the regression (ER; measure of accuracy) or slope bias, and error due to the disturbance (ED) or random error (Bibby and Toutenburg, 1977). These terms were calculated as:

$$
\begin{gathered}
E C T=(\bar{P}-\bar{O})^{2} \\
E R=\left(S_{p}-r \times S_{o}\right)^{2} \\
E D=\left(1-r^{2}\right) \times S_{o}^{2}
\end{gathered}
$$

214 Where $\bar{P}$ and $\bar{O}$ are the predicted and observed mean values, $S_{p}$ is the SD of predicted values, $215 S_{o}$ is the SD of observed values, and $r$ is the Pearson correlation coefficient.

\section{Concordance Correlation Coefficient}

217 The concordance correlation coefficient (CCC; Lin, 1989) was calculated as the product of $r$ 218 and a bias correction factor $\left(\mathrm{C}_{\mathrm{b}}\right.$, measure of accuracy): 


$$
C C C=r \times C_{b}
$$

where $C_{b}$ indicates how far the best fit line deviates from the concordance or unity line of the observed values versus predicted values plot. The $C_{b}$ ranges from 0 to 1 with greater values indicating less deviation from the concordance line. Large value of $\mathrm{CCC}$ indicates better 223 performance of model prediction.

224 RMSPE to standard deviation of observed values ratio (RSR)

When different data are used to compare the performance of models, the ratio of RMSPE and SD, should be used because it takes into account the data variability (Moriasi et al., 2007).

$$
\mathrm{RSR}=\mathrm{RMSPE} / \mathrm{SD} \text { of observed values of } \mathrm{CH}_{4}
$$

In this study, the performance of models with different numbers of data was ranked first by RSR and then by RMSPE\%.

\section{Results}

\subsection{Descriptive statistics of data}

232 The descriptive statistics of our database by ruminant category are presented in Table 1. Overall, 233 the database included a wide range in animal body weight, feed intake, diet composition, and $234 \mathrm{CH}_{4}$ emission. The dairy cattle included in the database produced, on average, $389 \mathrm{~g} \mathrm{of} \mathrm{CH}_{4} / \mathrm{d}$ ( $\mathrm{n}=2147), 20.5 \mathrm{~g}$ of $\mathrm{CH}_{4} / \mathrm{kg}$ DMI $(\mathrm{n}=1975)$ and $14.3 \mathrm{~g}$ of $\mathrm{CH}_{4} / \mathrm{kg}$ of fat and protein corrected milk (FPCM; $\mathrm{n}=1733$ ). Enteric $\mathrm{CH}_{4}$ emissions expressed as a percentage of GEI (Ym) was 6.12\%. Only 14.5, 0 and $11.5 \%$ of the EUR, US and AU dairy diets were $100 \%$ forage-based, 238 respectively. On average, EUR, US and AU dairy cattle were fed diets with 37.4, 48.9 and 37.8 $239 \mathrm{~g}$ of EE/kg DM, respectively.

240 Beef cattle produced $202 \mathrm{~g} \mathrm{CH}_{4} / \mathrm{d}$ on average and the $\mathrm{Ym}$ was $6.99 \%$. The forage proportion 241 was 0.70 of the diet resulting in an average DMI of $8.8 \mathrm{~kg} / \mathrm{d}$. Some high-grain diets (concentrate 242 proportion $>0.85$ ) were included $(6 \%$ of data). Most common ingredients in beef diets were 243 corn, wheat and grass silage (present in $60 \%$ of the observations) and cereal straw (32\% of the 
244 observations). The $\mathrm{CH}_{4}$ emissions and $\mathrm{Ym}$ value were $19.3 \mathrm{~g} / \mathrm{d}$ and $5.45 \%$ for sheep, and 14.2

$245 \mathrm{~g} / \mathrm{d}$ and $4.20 \%$ for goats, respectively. The average proportion of forage in the diet was 0.76 for 246 sheep and 0.36 for goats. The contents of EE, NDF and dOM in diets for sheep and goats were 24731 vs. 29 g/kg DM, 504 vs. 380 g/kg DM and 645 vs. $757 \mathrm{~g} / \mathrm{kg} \mathrm{DM}$, respectively.

\subsection{Performance of the models}

\subsubsection{Dairy Cattle}

250 Of the 40 existing equations evaluated using the dairy cattle data, only the 11 models with the smallest RSR (RSR $\leq 1)$ as well as the IPCC_1997 and IPCC_2006 Tier 2 models (used as reference) are listed in Table 3. Overall, equations based on feed intake (DMI, GEI and feeding level (DMI/BW)) had the smallest RSR of predicting $\mathrm{CH}_{4}$ emissions from dairy cattle. All models revealed a positive relationship between feed intake and daily $\mathrm{CH}_{4}$ emissions. Two models (Ramin_1 and Ramin_2) from Ramin and Huhtanen (2013) had low RSR (0.66 and 0.76, respectively) and RMSPE\% (15.6 and 21.2\%), and more than $90 \%$ of the prediction error due to random error. These two models also showed small mean bias $(0.70$ and $6.30 \%$, respectively) with CCC values of 0.75 and 0.57 , for Ramin_1 and Ramin_2 respectively. Mills_3, a nonlinear equation from Mills et al. (2003; see Table 2), resulted in the third ranked RSR (0.78), and in 21.8\% of RMSPE\%. A similar result was obtained by IPCC_1997, which had the fourth ranked RSR (0.79) and the CCC value of 0.68 . The mean bias obtained from the prediction of IPCC_1997 was 0.10\%, which was smaller than the mean bias observed in Mills_3 (11.7\%), but the slope bias was greater (12.8 vs. 1.5\%, respectively). Ellis et al. (2007) proposed models with different levels of complexity for dairy cattle and one of those models (Ellis_3), 265 presented the fifth ranked RSR (RSR $=0.80$, RMSPE $\%=22.7 \%$ and $\mathrm{CCC}=0.60$ ). Decomposition of the error indicated an $11.5 \%$ mean bias. This model included DMI, NDF intake (NDFI) and acid detergent fiber intake (ADFI) and had smaller RSR than the three simple models that only included one of the three predictors (models not shown in Table 3; RSR of 
Ellis_3 vs. Ellis_1, Ellis_2 and Ellis_4 was 0.80 vs. 0.87, 1.06 and 1.28, respectively). In 270 addition, Ellis' simple models produced a larger mean bias than the complex model. The models 271 of Charmley et al. (2016) for dairy cattle based on GEI or DMI produced similar RSR (0.81), 272 which was similar to the RSR produced by IPCC_1997. The decomposition of RMSPE made 273 by the models of Charmley et al. (2016) showed that at least $81.0 \%$ of the error was due to 274 random effects. The linear models by Mills et al. (2003; Mills_2 and Mills_1) had the $9^{\text {th }}$ and $27510^{\text {th }}$ ranked RSR and CCC values of 0.62 and 0.68 , respectively. The Mills_2 model was associated with the second smallest RMSPE\% (17.8\%) among all models, however it was ranked $9^{\text {th }}$ considering its greater $\mathrm{RSR}$, due to the small variability of observed $\mathrm{CH}_{4}$ values. The $11^{\text {th }}$ and $12^{\text {th }}$ ranked models in Table 3 are complex models from Ramin and Huhtanen (2013) and Sauvant et al. (2011). They represent the only models including dOM in the diet. The 280 updated Tier 2 model of IPCC (IPCC_2006) relating GEI and $\mathrm{CH}_{4}$ outputs was the last ranked model with a RSR of 0.87 .

The two subsets of low- and high-EE (under and over $39.3 \mathrm{~g}$ of EE/kg DM, respectively) diets in the dairy cow data were created to enable assessment of the ability of the models to predict difference in emissions caused by differences in concentrations of dietary lipids. These two data subsets had mean dietary EE contents of 30.4 vs. $51.7 \mathrm{~g} / \mathrm{kg}$ DM, respectively, and mean $\mathrm{CH}_{4}$ yields and intensities of 20.9 vs. $18.8 \mathrm{~g} / \mathrm{kg}$ DMI, and 15.7 vs. $12.4 \mathrm{~g} / \mathrm{kg}$ of milk, respectively (see Appendix A). A numerical difference in Ym was also observed (6.42 vs. 5.68\%, for the low- vs. the high-EE subsets, respectively). Models that specifically included lipid content as 289 one of the variables showed the smallest RSR and RMSPE among all models tested with the 290 high-EE subset (Figure 1). The models Ramin_1 and Ramin_3 maintained their RSR and 291 RMSPE\% (RSR $=0.73$ and 0.83, respectively, and RMSPE\% $=16.1$ and 20.3\%, respectively) 292 in the high-EE diets compared with their RSR and RMSPE\% using all dairy diets, whereas the 293 RSR of IPCC_1997 increased from 0.79 to 1.05. The Moraes model showed large RSR (0.95), 
with considerable mean bias (27.8\%). All models gave larger CCC values using all dairy diets

295 than when only the high-EE diets were used.

296 The subsets of low-NDF and high-NDF diets (under and over $350 \mathrm{~g} \mathrm{NDF} / \mathrm{kg} \mathrm{DM}$, respectively) 297 of dairy cattle had mean NDF contents of 285 and $433 \mathrm{~g} / \mathrm{kg} \mathrm{DM}$, respectively (Appendix B). 298 Other factors varied between the low- and the high-NDF subsets as $\mathrm{CH}_{4}$ emissions (405 vs. 385 $299 \mathrm{~g} / \mathrm{d}), \mathrm{CH}_{4}$ yield (18.6 vs. $\left.22.5 \mathrm{~g} / \mathrm{kg} \mathrm{DMI}\right), \mathrm{CH}_{4}$ intensity (12.9 vs. $16.2 \mathrm{~g} / \mathrm{kg}$ of milk), $\mathrm{Ym}(5.64$ 300 vs. $6.79 \%)$, DMI (22.2 vs. $17.4 \mathrm{~kg} / \mathrm{d})$ and GEI (409 vs. $331 \mathrm{MJ} / \mathrm{d})$, respectively. Using the low301 NDF subset, Ramin_1 resulted in RSR of 0.48, RMSPE\% of $10.1 \%$ and a CCC of 0.88 . Using 302 the high-NDF subset, Ellis_3 had the smallest RSR (0.54) and RMSPE\% (17.6\%) (Figure 2). 303 Based on the obtained RSR and RMSPE\%, the IPCC Tier 2 models performed better with the 304 high-NDF $(\mathrm{RSR}=0.68$ and 0.57, RMSPE\% $=16.9$ and 14.3\%, for IPCC_1997 and IPCC_2006, 305 respectively) than with the low-NDF diets (RSR $=1.06$ and $1.31, \mathrm{RMSPE} \%=23.7$ and $29.2 \%$, 306 for IPCC_1997 and IPCC_2006, respectively). The existing models, except Ramin_1, had 307 smaller RSR at high NDF level in the diet (from 0.54 to 0.63 ) than at low NDF level (RSR > 308 0.95).

309 The two subsets representing low- and high-STA diets (under and over $101 \mathrm{~g}$ of STA/kg DM) 310 for dairy cattle are presented in Appendix C. The low- and the high-STA diets had average STA 311 concentrations of 56 and $215 \mathrm{~g} / \mathrm{kg}$ DM of STA respectively. The $\mathrm{CH}_{4}$ emissions, yields and 312 intensities in the low- and the high-STA subsets were 364 vs. 415 g/d, 22.7 vs. 20.4 g/kg DMI 313 and 17.1 vs.14.1 g/kg of milk, respectively. The feed intakes (on DM basis) in the low- and the 314 high-STA subsets were 16.1 vs. $20.8 \mathrm{~kg} / \mathrm{d}$ and the Ym values were 6.73 vs. $6.17 \%$, respectively. 315 In general, all models had smaller RMSPE\% for the low-STA diets (RMSPE\%: 11.9 to 16.4\%) 316 than for the high-STA diets (RMSPE\%: 18.2 to 26.1\%). However, the RMSPE decomposition 317 revealed greater mean bias and smaller slope bias in the low- than the high-STA subsets (Figure 318 3). The ranking of models did not change between the low- and the high-STA subsets with the 
exception of IPCC_2006, which had the smallest RSR (0.80) for the low-STA diets but the 320 greatest RSR (1.04) for the high-STA diets.

321 The two subsets representing the low- and the high-quality diets using either dOM (under and over $720 \mathrm{~g} / \mathrm{kg} \mathrm{DM}$, respectively) or dNDF (under and over $600 \mathrm{~g} / \mathrm{kg} \mathrm{DM}$ ) are described in Appendices D and E, respectively. At the low- and the high-dOM (mean: 679 and $767 \mathrm{~g} / \mathrm{kg} \mathrm{DM}$, respectively), Ellis_3 and Ramin_1 models had the smallest RSR and the greatest CCC for predicting $\mathrm{CH}_{4}$ emissions from dairy cattle (Figure 4; Table 4). At the low dNDF, the same two models showed small RSR and RMSPE\%, and greatest CCC (RSR $=0.67$ and 0.78, RMSPE\% $=19.9$ and $16.7 \%, \mathrm{CCC}=0.71$ and 0.70 , respectively). Ramin_1 had a smaller RMSPE\% compared with Ellis_3, but the adjustment of the RMSPE by the SD of observed values of $\mathrm{CH}_{4}$ made Ellis_3 the highest ranked model. The evaluated models in both subsets (the low- and the

330 high-dNDF diets) generally showed acceptable RSR and RMSPE\% and were more accurate for the high-dNDF diets. All RSR obtained from the high-dNDF subset were smaller than those obtained from the low-dNDF subset. The RSMPE\% obtained by the best five models in the high-dNDF subset had a small range (13.3 to $18.4 \%)$. Ellis_3 showed good predictive ability in

334 both subsets considering its small RSR (0.67 and 0.59 in the low- and the high-dNDF subsets, 335 respectively), RMSPE\% < 20\% and almost null mean and slope biases (Figure 5). Ramin_3 gave the smallest RSR for the high-dNDF subset, resulting in similar RSR with Ellis_3 (0.59)

337 but smaller RMSPE\%. Mills_2 had 13.5\% of RMSPE\% and the third smallest RSR although it 338 had a 24.6\% mean bias. The IPCC_2006 was associated with the fourth RSR for the high-dNDF 339 diets.

\section{3.2.2. Beef cattle}

341 For beef cattle, 21 models were evaluated using the beef cattle data. Table 5 presents the 10 342 models with the smallest $\mathrm{RSR}(\mathrm{RSR} \leq 1)$ to predict $\mathrm{CH}_{4}$ emissions from beef cattle. The model 343 from Escobar-Bahamondes et al. (2017a) resulted in the smallest RSR (0.83) and RMSPE\% 
$344(27.2 \%)$ among all models, with $93.6 \%$ of the RMSPE due to random errors and CCC value of 345 0.40. Among the feed intake-based models, Ramin_2, Yan_1, Yan_2 and IPCC_2006 had 346 similar results. The RSR of these models ranged from 0.84 to 0.87 and RMSPE\% from 32.7 to $34734.0 \%$. The remaining models presented in Table 5 had low predictive ability considering the 348 large RMSPE\% (> 33\%) and the large mean bias (from 17.5 to $22.1 \%$ ).

349 The descriptions of the low- and the high-EE subsets (under and over $40 \mathrm{~g}$ of EE/kg DM, 350 respectively) of beef cattle are shown in Appendix F. The average of EE content in each subset was 25.3 and $58.4 \mathrm{~g} / \mathrm{kg} \mathrm{DM}$, respectively. The emissions and yields of $\mathrm{CH}_{4}$ in the low- and the high-EE diets were 252 vs. $188 \mathrm{~g} / \mathrm{d}$, and 26.9 vs. 23.4, respectively. When models were evaluated using each subset separately (Table 6), the ranking was the same, with the EscobarBahamondes et al. (2017a) model having the smallest RSR followed by the models of Grainger and Beauchemin (2011), IPCC_2006 and IPCC_1997. The RSR values of all models were slightly smaller at the low- than at the high-EE diets. Large prediction errors were observed for all models at high EE content (RMSPE\% > 33\%). The predictions by Tier 2 models of IPCC are associated with large RMSPE\% (from 33 to 37\%) and large mean biases (from 31 to 45\%) in the high-EE subset. The CCC of all predicting models were smaller for the high-EE than for 360 the low-EE diets. Similar to lipid supplementation strategy, the models were evaluated when 361 low- or high-NDF diets were fed to beef cattle (under and over $338 \mathrm{~g}$ of NDF/kg DM, 362 respectively). In both the low- and the high-NDF diets (Appendix G), again the Escobar363 Bahamondes et al. (2017a) model showed the smallest RSR in the prediction of $\mathrm{CH}_{4}$ emissions 364 from beef cattle. The RSR of this model was slightly smaller at high NDF than at low NDF 365 content (0.84 vs. 0.86, respectively). The IPCC_2006 and IPCC_1997 models were associated with large RSR (from 0.88 to 0.98), RMSPE\% (from 31 to $40.5 \%$ ) and mean biases from 3.1 to $31.6 \%$. When differences in dietary STA were taken into account (threshold $=110 \mathrm{~g}$ of STA/kg DM; see Appendix H), the IPCC models presented the smallest RSR among all models, 
although their prediction of $\mathrm{CH}_{4}$ emissions was associated with large RSR (> 1) and RMSPE\%

370 (> 32\%); and small CCC (0.38). Diet composition and $\mathrm{CH}_{4}$ emissions in each data subset of the 371 low- and the high-dOM or dNDF (under and over 745 and $600 \mathrm{~g} / \mathrm{kg} \mathrm{DM}$, for dOM and dNDF

372 respectively) for the beef data are shown in Appendices I and J, respectively. The smallest RSR 373 was obtained by Ellis_5 model at the low-dOM and by IPCC_1997 at the high-dOM diets (RSR $374=0.71)$. However, using $\mathrm{dNDF}$ as an indicator of diet quality, the smallest RSR was obtained 375 by IPCC_2006 with both, the low- and the high-dNDF diets (Table 6).

\subsubsection{Small ruminants}

377 The six evaluated models with RSR $<1$ using sheep data, ranked by RSR, are shown in Table 7. The Patra_3 model had the smallest RSR (0.61) with the RMSPE\% being $19.2 \%$, most of which was due to random sources. The correlation coefficient $(r)$ between observed and 380 predicted values by Patra_3 was 0.81 , resulting in the largest CCC (0.75) in Table 7 . The IPCC_1997 and Patra_2 models were both based on GEI and were ranked $2^{\text {nd }}$ and $3^{\text {rd }}$, respectively. The RSR and RMSPE\% obtained from IPCC_1997 and Patra_2 were similar (0.77 vs. $0.78 ; \operatorname{RMSPE} \%=26.8$ and $27.2 \%$, respectively). In comparison to the IPCC_1997 and

384 Patra_2 models, the other models were all associated with greater RSR ( 0.85 on average) and 385 greater RMSPE\% (around 30\%). IPCC_1997 had greater precision and accuracy in predicting $\mathrm{CH}_{4}$ than IPCC_2006.

387 The evaluated models were less accurate at predicting $\mathrm{CH}_{4}$ emissions for goats than they were 388 for sheep (Table 8). Three models from Patra and Lalhriatpuii (2016) resulted in large RSR 389 (from 0.86 to 0.98 ) and large RMSPE\% (from 38 to 43\%). The model from FAO reports (2010) 390 based on digestibility of dry matter was associated with a large RSR (1.22) and RMSPE\% $391(65.4 \%)$. 
393 Results of the comparison between models developed from individual records or treatment 394 means are shown in Table 9. The four models with the smallest RSR values based on individual 395 records in dairy cattle (all diets) were IPCC_1997, Charmley_2, Charmley_1, and IPCC_2006, 396 and the four models with the smallest RSR values based on treatment mean records were 397 Ramin_1, Ramin_2, Ellis_3, and Sauvant_1. The range in values of RSMPE\% for individual 398 record models was smaller than that for mean record models (21.2 to $23.4 \%$ vs. 15.6 to $27.4 \%$, 399 respectively). When both types of models (individual and treatment means) were evaluated 400 using the 'treatment means' database, the RMPSE\% of individual and means models varied 401 from 16.9 to $18.7 \%$ and from 13.7 to $20.2 \%$, respectively. Moreover, the values of RMSPE\% 402 for each individual record and mean record model were decreased when evaluated using the 403 mean database compared with when evaluated using the individual database.

404 The SD of the observed values of $\mathrm{CH}_{4}$ emissions in the 'treatment means' database was smaller 405 than that determined in the individual record database. In general, the ranking of the means models was higher than that of individual record models when evaluated either by the individual or 'treatment means' databases.

\section{Discussion}

409 In the current research, we aimed to identify the models that had the smallest prediction error 410 of $\mathrm{CH}_{4}$ emissions and fitted our data, based on the smallest RSR and RMSPE\%. We evaluated 411 a large number of published models to estimate $\mathrm{CH}_{4}$ emissions for different ruminant categories 412 under diverse dietary regimes. The database generated by the GLOBAL NETWORK project 413 comprised > 3000 individual data from 103 studies and is the largest ever used in such model 414 evaluation. Previous studies have evaluated models for a single ruminant category (e.g., either 415 dairy cattle, beef cattle or feedlot cattle; Kebreab et al., 2008; Ellis et al., 2010; Escobar416 Bahamondes et al., 2017b) or models based on regional data obtained from the scientific 417 literature and based on treatment means (Appuhamy et al., 2016). This is the first evaluation of 
models using a large database based on data from individual animals of all major livestock

419 species and breeds and the data were from experiments that have been conducted in various 420 countries in which diverse nutritional strategies to mitigate $\mathrm{CH}_{4}$ emissions have been tested.

421 The domain of application of each model has been respected and the performance obtained 422 reflects the goodness of fit between the $\mathrm{CH}_{4}$ predictions and $\mathrm{CH}_{4}$ observed values in our 423 database. It should be pointed out that some dietary variables used by the evaluated model were 424 not measured in all included studies, therefore the models were evaluated against different 425 numbers of observations. In this study, we present the results of evaluations using maximal data 426 for each model and chose the statistical parameter "RSR" to compare models evaluated using 427 different datasets.

428 Some of the selected models are specific to certain ruminant categories, whereas others are 429 developed to estimate $\mathrm{CH}_{4}$ emissions in different ruminant categories (IPCC, 1997 and 2006; 430 Sauvant et al,. 2011; Ramin and Huhtanen, 2013). At the moment, although the IPCC Tier 2 431 models are primarily used to provide estimates of $\mathrm{CH}_{4}$ emissions in national inventories of $\mathrm{CH}_{4}$ 432 emissions, their adequacy for dairy cattle (Appuhamy et al., 2016; Niu et al., 2018), as well as 433 for feedlot and beef cattle (Kebreab et al., 2008), and for small ruminants (Patra et al., 2016; 434 Patra and Lalhriatpuii, 2016) has been debated. In this research, we have compared the accuracy 435 of the IPCC Tier 2 models with those of other models from the scientific literature using data 436 for different nutritional strategies for $\mathrm{CH}_{4}$ mitigation, as well as different ruminant categories.

\subsection{Dairy cattle}

438 The smallest error of prediction of $\mathrm{CH}_{4}$ emissions from dairy cattle (by the smallest RSR and 439 RMSPE\%) were obtained from the models developed in Ramin and Huhtanen (2013), Mills et 440 al. (2003), IPCC (1997) and Charmley et al. (2016). In general, they all use feed intake (DMI, 441 GEI or feeding level (DMI/BW)) as a predictor variable. This is in agreement with feed intake 442 being the key factor driving $\mathrm{CH}_{4}$ emissions (Reynolds et al., 2011; Hristov et al., 2013; Niu et 
443 al., 2018). Moreover, the DMI can explain at least $70 \%$ of variation in $\mathrm{CH}_{4}$ emissions from 444 cattle (Ricci et al., 2013) through a positive linear relationship between DMI and the daily $\mathrm{CH}_{4}$ 445 emissions rate (g/d), using the slope to reflect the changes in $\mathrm{CH}_{4}$ with DMI or the $\mathrm{CH}_{4}$ yield 446 ( $\mathrm{g} \mathrm{CH}_{4} / \mathrm{kg} \mathrm{DMI}$ ) with or without intercept (Dijkstra et al., 2011; Charmley et al., 2016). 447 However, Ramin_2 and Mills_3 performed better than other DMI-based models since it 448 included a curvilinear effect of DMI at large feed intake (Figure 6). The curvilinear effect may 449 be due to the high passage rate of solid matter out of the rumen (Knapp et al., 2014) and the 450 effect of a high proportion of concentrate which are hallmarks of diets associated with large 451 feed intake (Rotz et al., 2011). These two models also captured the effect of the shift in 452 fermentation pattern from more acetogenic to more propiogenic at increased DMI (Robinson et 453 al., 1986), especially for diets containing a large fraction of rapidly fermentable carbohydrates 454 by the indirect effect of $\mathrm{pH}$ on volatile fatty acids (Bannink et al., 2008). Janssen (2010) 455 discussed the negative effect of a large concentration of dissolved $\mathrm{H}_{2}$ in the rumen on the $\mathrm{CH}_{4}$ 456 formation, especially in animals having a large intake of readily fermentable feed. However, 457 Ramin_2 resulted in smaller CCC than Mills_3 due to its under-prediction of $\mathrm{CH}_{4}$ emissions 458 when emissions are greater than $600 \mathrm{~g} / \mathrm{d}$.

459 The overall smallest RSR and RMSPE, and the largest CCC and $\mathrm{r}$ were obtained from the 460 prediction made by the model Ramin_1. This performance can be explained by the inclusion of 461 three factors that affect ruminal $\mathrm{CH}_{4}$ production: the feeding level (DMI/BW), energy 462 digestibility (dGE) and dietary lipid (EE) content. The importance of dGE as a key factor to 463 estimate $\mathrm{CH}_{4}$ emissions has been long known (Blaxter and Clapperton, 1965). Other studies 464 have suggested that the use of $\mathrm{dOM}$ instead of energy digestibility to better predict $\mathrm{CH}_{4}$ 465 emissions from ruminants (Bell et al., 2016) because $\mathrm{CH}_{4}$ is produced in the rumen by the 466 fermentation of OM (Sauvant et al., 2011). However, in the present evaluation, two models 
include dOM (e.g., Ramin_3 and Sauvant_1) as a predictor, but they showed less precision and accuracy than the model of Ramin_1 which is based on dGE.

In agreement with Niu et al. (2018), the Ym value of $6 \%$ of GEI being converted into $\mathrm{CH}_{4}$ and introduced in IPCC_1997 model, provided a more accurate prediction for dairy cattle across regions than the Ym of 6.5\% introduced in IPCC_2006 model. Kebreab et al. (2008) and Appuhamy et al. (2016) pointed out that the Tier 2 model of the IPCC (2006) could overestimate $\mathrm{CH}_{4}$ emissions in dairy cattle. The average $\mathrm{Ym}$ for dairy cattle in our database was $6.12 \%$, which was closer to the IPCC_1997 value. More complex models based on Tier 3 methodology indicate that a Ym value of 6\% is more realistic than a 6.5\% (Bannink et al., 2011). Both IPCC models are based on GEI only and do not capture the effect of changes in the composition of the diet and therefore show a limited ability to estimate the difference in $\mathrm{CH}_{4}$ emissions under different nutritional strategies (Ellis et al., 2010). Also, the present results support this argument when the IPCC models were challenged against data from diets with different concentrations of lipid, STA or digestible DM.

\section{Dietary lipid content}

The negative effect of high dietary EE concentration on the absolute $\mathrm{CH}_{4}$ emissions (g/d) did not become apparent from the data analysis because of the concomitantly greater feed intake in the high- than in the low-EE subset (22.7 vs. $18.2 \mathrm{~kg}$ of DM/d, respectively). The daily $\mathrm{CH}_{4}$ emissions are determined primarily by the amount of feed intake and, for this reason, the effect of lipid supplementation is better assessed based on $\mathrm{CH}_{4}$ yield. On this basis, the $\mathrm{CH}_{4}$ yield for the low- and the high-EE diets were 20.9 and $18.8 \mathrm{~g} / \mathrm{kg}$ of DMI. In addition, a numerical effect of EE on Ym was observed, with Ym about 12.5\% smaller in the high- than in the low-EE subsets $(\mathrm{Ym}=5.68$ vs. $6.42 \%)$. Moreover, the average of fiber intake (NDF intake, $\mathrm{g} / \mathrm{d})$ was larger in the high-EE than in the low-EE subsets, which likely counterbalanced the effect of lipid supplementation. Dietary lipids have been reported to reduce $\mathrm{CH}_{4}$ emissions (Beauchemin 
et al., 2008; Moate et al., 2011). Some authors reported that lipid sources (Knapp et al., 2014)

493 or fatty acids profile (Giger-Reverdin et al., 2003) have an effect as well, but this was not a 494 major source of variation based on the meta-analysis made by Beauchemin et al. (2008). In the current research, the results related to lipid supplementation strategy are in agreement with the results reported by Beauchemin et al. (2008), Martin et al. (2010) and Moate et al. (2011) who 497 showed that the addition of $10 \mathrm{~g} \mathrm{EE} / \mathrm{kg}$ DM led to $5.6 \%$ and $3.8 \%$ and $3.5 \%$ lower $\mathrm{CH}_{4}$ yield $498(\mathrm{~g} / \mathrm{kg} \mathrm{DM})$, respectively. The negative effect of dietary lipids on daily $\mathrm{CH}_{4}$ emissions $(\mathrm{g} / \mathrm{d})$ was 499 also reported in the meta-analysis of Eugène et al. (2008), where the average EE contents in the low- and the high-EE subsets were 25 and $64 \mathrm{~g} / \mathrm{kg}$ DM, respectively. However, that effect was 501 due to the lower DMI associated with the high dietary lipid content. The Ramin_1 model 502 includes both DMI and dietary lipid content (EE), and this may explain the small prediction 503 error (RSR and RMSPE \%) of Ramin_1 with both the global dairy dataset and with the high504 EE subset. Some models from Grainger and Beauchemin (2011) and Nielsen et al. (2013) 505 performed well with the low-EE dataset but not the high-EE dataset. The model by Nielsen et al. (2013) uses total fatty acid content instead of EE content. In the current research we 507 estimated in total fatty acid content from EE content using an equation from Giger-Reverdin et 508 al. (2003), and this may have introduced error and hence lower prediction performance by these 509 models.

510 The IPCC_1997 and IPCC_2006 models had small RSR (0.78 and 0.80, respectively), small 511 RMSPE\% (17.1 and 17.6\%, respectively) and large CCC (0.71) in the low-EE subset but large 512 RSR and RMSPE\% and small CCC in the high-EE subset (RSR > 1, RMSPE\% > 25\% and 513 CCC < 0.50). Cows fed the low-EE diets $(\mathrm{EE}<39.3 \mathrm{~g} / \mathrm{kg} \mathrm{DM})$ had a Ym value of $6.42 \%$ in our 514 database ( $\mathrm{n}=685$ observations), which is close to the value of $6.5 \%$ adopted in IPCC (2006). 515 On the contrary, the Ym of the high-EE diets was 5.68\% ( $\mathrm{n}=490$ observations) which is 516 substantially smaller than the value of 6\% adopted in the IPCC_1997 model. 
518 When dairy cattle were fed high-quality diets (assessed by dOM or dNDF) or low-NDF diets, 519 the Ellis_3 model based on DMI, NDFI and ADFI, outperformed Ramin_1 by the smaller RSR, 520 which is based on DMI, dGE and EE. This result indicates the importance of including variables 521 associated with structural carbohydrates if the model is to predict the effect of NDF content on

$522 \mathrm{CH}_{4}$ emissions from cattle. However, this effect may not depend only on structural carbohydrate, 523 as it can be often confounded by effects of DMI and the negative effect of dietary lipids on $\mathrm{dNDF}$, and the ratio of structural/non-structural carbohydrates in the diet (Moe and Tyrrell, 1979). Ramin_1 had a particularly good predictive ability for $\mathrm{CH}_{4}$ emissions from dairy cattle fed low NDF content diets indicated by a RMSPE of only $10.1 \%$ and CCC of 0.88 . Both IPCC models predicted $\mathrm{CH}_{4}$ emissions for the high-NFD diets better than for the low-NDF diets.

\section{Dietary starch content}

529 The models were also assessed for predicting $\mathrm{CH}_{4}$ emissions from dairy cow diets differing in STA content, which mainly originated from either cereals or silages (corn or barley). To split 531 the database into the low- and the high-STA subsets, we chose to use dietary STA content as a 532 criterion and not the dietary concentrate content. Consequently, STA from the inclusion of 533 cereal in the diet, but also from corn or barley silages, which are largely present in the database, were included. When substantial amounts of STA is fed to dairy cattle, it is more appropriate to include information about feed composition or digestibility in the model as in Mills_2 and Ramin_3 models, next to the feed intake. The Sauvant_1 model contains concentrate proportion 537 in the diet as a variable and its RSR was superior to 1 (not shown in Table 4) in predicting $\mathrm{CH}_{4}$ 538 emissions from cattle fed the high-STA diets in the present work. We surmise the proportion of concentrate in the diet is not precise enough to explain variation in $\mathrm{CH}_{4}$ emissions, and the

540 prediction models should introduce STA content. In addition, at the same content of STA in the 541 diet, the type of grain fed to dairy cattle has been reported to impact the $\mathrm{CH}_{4}$ emissions (Moate 
et al., 2017). However, more studies are required with direct comparisons between types of

543 starch. It is known that information about contents of dietary carbohydrate fractions (cellulose,

544 hemicellulose, lignin, STA and sugars) is useful to predict variation in $\mathrm{CH}_{4}$ emissions (Moe and

545 Tyrrell, 1979; Hindrichsen et al., 2005; Ellis et al. 2009). However, because of the unavailability

546 of data on cellulose, hemicellulose, lignin and sugars in our database, these models could not

547 be evaluated. The IPCC_1997 and IPCC_2006 models, based on GEI, resulted in 20 to $22 \%$ of

548 RSMPE\% for the high-STA diets. This can be explained by the capacity of GEI to capture STA

549 in the diet.

550 Diet quality

551 Feeding diets of high quality (i.e. digestibility) has been reported to reduce $\mathrm{CH}_{4}$ intensity $(\mathrm{g} / \mathrm{kg}$ 552 of milk) by increasing milk production per cow, diluting the amount of feed required per unit 553 of milk and changing rumen fermentation conditions (Knapp et al., 2014). The quality of diets

554 is partially determined by the cell-wall content and its digestibility (Jung and Allen, 1995).

555 However, at similar dietary NDF content, diet quality can still vary considerably (Broderick et 556 al., 2002), affecting feed intake, animal performance and $\mathrm{CH}_{4}$ emissions, yield and intensity. In 557 the present evaluation, diet quality was assessed using dOM and dNDF of the diet. Under the 558 variation of both diet quality factors (dOM and dNDF), Ellis_3 and Ramin_1 showed the 559 smallest RSR. Only one of the two IPCC models had good predictions of $\mathrm{CH}_{4}$ emissions with 560 small RSR and RMSPE for the high-quality diets depending on the criterion for diet quality 561 (the IPCC_1997 model for the high-dOM subset and the IPCC_2006 model for the high-dNDF 562 subset). In our database, dOM was affected by NDF, STA and EE contents in the diet. The 563 Ramin_3 model contains predictors that can account for effects associated with diet quality, 564 and it successfully reduced prediction error to $13 \%$. A similar model, but expanded using more 565 parameters related to diet quality (i.e. $\mathrm{dNDF}$ ), may be useful to better predict $\mathrm{CH}_{4}$ emission. 
The current research has mostly focused on predictive equations based on major nutrient

567 components in diets. Recently, research has shown that the inclusion of a small amount of 3568 nitrooxypropanol in the diet of cattle can result in a substantial, sustained reduction in $\mathrm{CH}_{4}$ 569 emissions (Hristov et al. 2015). We consider that if in the near future, 3-nitrooxypropanol is 570 registered for use in ruminants, predictive models that include 3-nitrooxypropanol as a predictor 571 will need to be developed.

\section{$572 \quad$ 4.2.Beef cattle}

573 Models evaluated in the beef category were associated with considerable prediction error (RMSPE > 34\%). This suggests new equations need to be developed for beef cattle. Given that all beef data in our study were from EUR, the effort of developing and updating equations should be focused on including an evaluation for this specific region as well. Furthermore, globally, the largest beef cattle herds are outside Europe and effort should also be directed towards the development of improved predictive equations suited to these regions. The smallest prediction error (considering RSR and RMSPE) with our beef data was obtained using the model from Escobar-Bahamondes et al. (2017a). However, the CCC associated with this model

581 was not the largest among the evaluated models for beef cattle. Originally, the Escobar582 Bahamondes et al. (2017a) model was developed using data from both high-forage and highgrain diets and it had a RMSPE\% of $12.1 \%$ of the observed mean $\mathrm{CH}_{4}$ emissions which was much smaller than the RMSPE\% of $27.2 \%$ obtained in the present evaluation. However,

585 Escobar-Bahamondes et al. (2017a) applied a cross-validation methodology using the same data 586 they used for the model development which may partly explain this observation. The DMI587 based model (Ramin_2) was less accurate for beef cattle than for dairy cattle, despite the fact that it was developed from a general database including data from both dairy and beef cattle, as well as sheep. 
Similar to the dairy cattle category, there was not a single model that predicted $\mathrm{CH}_{4}$ emissions

591 with small RSR and RMSPE in all nutritional mitigation strategies for beef cattle. The low performance of models tested for the individual nutritional mitigation strategies may be because all beef data were from EUR whereas the models were developed using data from US (Ellis et al., 2007 and 2009; Grainger and Beauchemin, 2011). The $\mathrm{CH}_{4}$ emissions (g/d) from beef cattle fed diets with high EE content (average $\mathrm{EE}=58.4 \mathrm{~g} / \mathrm{kg} \mathrm{DM}$ ) was $25 \%$ smaller than $\mathrm{CH}_{4}$ 596 emissions from beef cattle fed the low-EE diets (average EE $=25.3 \mathrm{~g} / \mathrm{kg} \mathrm{DM}$ ). Among all models evaluated for this ruminant category, the model from Escobar-Bahamondes et al. (2017a) achieved the most accurate prediction of $\mathrm{CH}_{4}$ emissions from lipid supplemented diets, and diets with different contents of NDF. This is in agreement with the results for dairy cattle where 600 complex models based on feed intake, digestibility and diet composition were also most 601 appropriate to predict $\mathrm{CH}_{4}$ emissions under different nutritional conditions. The model of 602 Escobar-Bahamondes et al. (2017a) lacks a variable for digestibility (of energy, OM or NDF), 603 which probably explains its large RSR and RMSPE, and its small CCC compared with the 604 model Ramin_1 for dairy cattle.

\subsection{Small ruminants}

606 Few specific models for small ruminants were found in the scientific literature. In addition to 607 IPCC and global models (Sauvant et al., 2011; Ramin and Huhtanen, 2013), the equations 608 evaluated were obtained from Patra et al. (2016) and Patra and Lalhriatpuii (2016). For sheep, 609 the smallest prediction errors based on the values of RSR and RMSPE were obtained from 610 Patra_3, based on digestible energy intake (DEI, MJ/d). The Patra_3 model was also associated 611 with the largest CCC and largest correlation (r) between observed and predicted values. This is 612 probably because it considered the relationship between energy digestibility and $\mathrm{CH}_{4}$ 613 production in the rumen, first reported half a century ago (Blaxter and Clapperton, 1965). For 614 goats, all the evaluated models showed moderate predictions given the RSR > 0.85 and the 
615 RMSPE\% > 37\% of the mean observed $\mathrm{CH}_{4}$ emissions. In sheep, IPCC_1997 was better at 616 predicting $\mathrm{CH}_{4}$ emissions than IPCC_2006. In a meta-analysis, IPCC_2006 was evaluated using 617 sheep data on 98 treatment means and the RMSPE was $23.1 \%$ of the mean $\mathrm{CH}_{4}$ emissions (Patra 618 et al., 2016). In our evaluation, IPCC_2006 had a slightly larger prediction error (RMSPE = $61930 \%, \mathrm{n}=111)$.

\subsection{Impact of the data source of models}

621 Models from Ramin and Huhtanen (2013) were applicable to different ruminant categories 622 (dairy and beef cattle, and sheep). They performed globally better than some category-specific models such as those from Grainger and Beauchemin (2011), Nielsen et al. (2013) as well as

624 Moraes et al. (2014) in the dairy category. Grainger and Beauchemin (2011) proposed both 625 category-specific (Grainger_3 from cattle) and across categories models to estimate the effect 626 of dietary fat on $\mathrm{CH}_{4}$ emissions from ruminants (Grainger_1 and Grainger_2). Similar RSR were observed from across-categories and cattle-specific models when they were evaluated using data from dairy and beef cattle fed lipid supplements. The present study only evaluated models developed since 2000. However, it is acknowledged that the model of Blaxter and Clapperton (1965) which was subsequently corrected by Wilkerson et al. (1995) as well as the model of Moe and Tyrrell (1979) were developed using data from cattle with or without small ruminants and their good predictive abilities have been well documented.

633 The use of databases containing either data from individual animals or treatment means in the 634 evaluation might lead to different conclusions about the performance of the same model (Ellis 635 et al., 2010). However, Ellis et al. (2010) used different sources to obtain their two evaluation 636 datasets, one for individual animal data and one for treatment mean data, and the difference in 637 the performance of one model when evaluated against these datasets may be due to the variation 638 in each dataset. Therefore, in the present study the treatment means database was created from 639 the original individual animal database to avoid such bias. The models developed on either 
640 individual animal data or treatment means data had smaller RSR when challenged against data

641 from individual animals than when challenged against treatment means data, because of the 642 greater variability or standard deviation of observed $\mathrm{CH}_{4}$ in individual animal data compared 643 with treatment means data (105 vs $74.3 \mathrm{~g} / \mathrm{d})$. Models derived from treatment means data had 644 smaller RSR than models derived from individual animal data. This might result from the 645 smoothing out of large individual variation when calculating means. Overall, our study 646 indicates that the performance of models (given by the RSR and RMSPE) does not as much 647 depend on the type of data used for the model development (individual animal records or 648 treatment means records), but essentially on the explanatory variables used in the model.

\subsection{Model prediction uncertainties}

650 Recent work from the GLOBAL NETWORK project (Hristov et al., 2018), reviewed the 651 uncertainties and discrepancies associated with the $\mathrm{CH}_{4}$ measurement techniques, expressed as coefficient of variation $(\mathrm{CV})$. A significant $\mathrm{CV}$ was associated with all measurement methods for $\mathrm{CH}_{4}$ yield $(\mathrm{g} / \mathrm{kg}$ of $\mathrm{DMI}): 21,27$ and $21 \%$ for respiration chambers, $\mathrm{SF}_{6}$ tracer technique and automated head chamber, respectively. This CV includes different sources of error (Hammond et al., 2016). The range of the prediction errors (RMSPE\%) obtained in this study from the empirical models were 15.6 to $23.4 \%$ for dairy cattle (all diets), 27.2 to $36.7 \%$ for beef cattle (all diets), 19.2 to $32.7 \%$ for sheep and 37.7 to $65.4 \%$ for goats. The different ranges of prediction error between animal categories can be associated with the different amount of data available for each category. Some evaluated models had smaller prediction error than the uncertainty associated with the measurement techniques (see Tables 3, 5 and 7).

\section{Conclusions}

662 From the empirical $\mathrm{CH}_{4}$ prediction models published since 2000, there is no unique model that accurately predicts $\mathrm{CH}_{4}$ emissions for all ruminant categories and for all nutritional strategies

664 designed to mitigate $\mathrm{CH}_{4}$ emissions. With our database, the IPCC (1997) Tier 2 model generally 
665

666

performed better than the updated IPCC (2006) model for the different ruminant categories and nutritional strategies evaluated in this study. Using our database, both IPCC models performed moderately under different mitigation strategies because they do not account for differences in dietary lipid, NDF and STA contents, and the effects of diet quality (i.e., digestibility). The models of Ramin and Huhtanen (2013) demonstrated a good predictive ability to estimate $\mathrm{CH}_{4}$ emissions from dairy cattle. The model of Escobar-Bahamondes et al. (2017a) showed good predictive performance when applied to beef cattle fed diets with different contents of EE and NDF. The explanatory factors used in the model have more impact on its performance than the type of data (individual data vs. treatment means) used in the development or in the evaluation. Based on the results from our dataset, some empirical models give satisfactory predictions compared with the error associated with $\mathrm{CH}_{4}$ emissions measurement methods. More data and modeling efforts are needed to better predict $\mathrm{CH}_{4}$ emissions from beef cattle and small ruminants. For future model development, it is recommended to take into account nutritional strategies designed to mitigate $\mathrm{CH}_{4}$ emissions.

\section{Acknowledgements}

This study is part of the Joint Programming Initiative on Agriculture, Food Security and Climate Change (FACCE-JPI)'s "GLOBAL NETWORK" project and the "Feeding and Nutrition Network" (http://animalscience.psu.edu/fnn) of the Livestock Research Group within the Global Research Alliance for Agricultural Greenhouse Gases (www.globalresearchalliance.org). Authors gratefully acknowledge funding for this project from: USDA National Institute of Food and Agriculture Grant no. 2014-67003-21979) University of California, Davis Sesnon Endowed Chair Program, USDA, and Austin Eugene Lyons Fellowship (University of California, Davis); Funding from USDA National Institute of Food and Agriculture Federal Appropriations under Project PEN 04539 and Accession number 
691 (Harrisburg, PA, USA), Northeast Sustainable Agriculture Research and Education (Burlington, VT, USA), and PMI Nutritional Additives (Shoreview, MN, USA); the Ministry of Economic Affairs (the Netherlands; project BO-20-007-006; Global Research Alliance on Agricultural 694 Greenhouse Gases), the Product Board Animal Feed (Zoetermeer, the Netherlands) and the 695 Dutch Dairy Board (Zoetermeer, the Netherlands); USDA National Institute of Food and 696 Agriculture (Hatch Multistate NC-1042 Project Number NH00616-R; Project Accession 697 Number 1001855) and the New Hampshire Agricultural Experiment Station (Durham, NH); 698 French National Research Agency through the FACCE-JPI program (ANR-13-JFAC-0003-01); 699 the Department of Agriculture, Food and the Marine, Ireland Agricultural GHG Research 700 Initiative for Ireland (AGRI-I) project; Academy of Finland (No. 281337), Helsinki, Finland; 701 Swiss Federal Office of Agriculture, Berne, Switzerland; the Department for Environment, 702 Food and Rural Affairs (Defra; UK); Defra, the Scottish Government, DARD, and the Welsh 703 Government as part of the UK's Agricultural GHG Research Platform projects 704 (www.ghgplatform.org.uk); INIA (Spain, project MIT01-GLOBALNET-EEZ); German 705 Federal Ministry of Food and Agriculture (BMBL) through the Federal Office for Agriculture 706 and Food (BLE); Swedish Infrastructure for Ecosystem Science (SITES) at R€ob€acksdalen 707 Research Station; Comisi_on Nacional de Investigaci_on Cient_ifica y Tecnol_ogica, Fondo 708 Nacional de Desarrollo Cient_1fico y Tecnol_ogico (Grant Nos. 11110410 and 1151355) and 709 Fondo Regional de Tecnología Agropecuaria (FTG/RF-1028-RG); European Commission 710 through SMEthane (FP7-SME-262270). The authors are thankful to all colleagues who 711 contributed data to the GLOBAL NETWORK project. All authors read and approved the final 712 manuscript. The authors declare that they have no competing interests.

\section{References}

714 Appuhamy, J.A.D.R.N., France, J., Kebreab, E., 2016. Models for predicting enteric methane 
emissions from dairy cows in North America, Europe, and Australia and New Zealand. Glob. Chang. Biol. 22, 3039-3056. https://doi.org/10.1111/gcb.13339

Archimède, H., Eugène, M., Marie Magdeleine, C., Boval, M., Martin, C., Morgavi, D.P., Lecomte, P., Doreau, M., 2011. Comparison of methane production between C3 and C4 grasses and legumes. Anim. Feed Sci. Technol. 166-167, 59-64. https://doi.org/10.1016/j.anifeedsci.2011.04.003

Bannink, A., Kogut, J., Dijkstra, J., France, J., Kebreab, E., Van Vuuren, A.M.,Tamminga, S., 2006. Estimation of the stoichiometry of volatile fatty acid production in the rumen of lactating cows. Journal of Theoretical Biology 238, 36-51. https://doi.org/10.1016/j.jtbi.2005.05.026

Beauchemin, K.A., Kreuzer, M., O’Mara, F., McAllister, T.A., 2008. Nutritional management for enteric methane abatement: A review. Aust. J. Exp. Agric. 48, 21-27. https://doi.org/10.1071/EA07199

Bell, M., Eckard, R., Moate, P.J., Yan, T., 2016. Modelling the effect of diet composition on enteric methane emissions across sheep, beef cattle and dairy cows. Animals 6, 1-16. https://doi.org/10.3390/ani6090054

Bibby, J., Toutenburg, H., 1977. Prediction and improved estimation in linear models. Chichester, UK: John Wiley and Sons. https://doi.org/10.1002/bimj.197800029

Blaxter, K., Clapperton, J., 1965. Prediction of the amount of methane produced by ruminants. Br. J. Nutr. 19, 511-522. https://doi.org/10.1079/BJN19650046

Broderick, G.A., Koegel, R.G., Walgenbach, R.P., Kraus, T.J., 2002. Ryegrass or alfalfa silage as the dietary forage for lactating dairy cows. J. Dairy Sci. 85: 1894-1901. https://doi.org/10.3168/jds.S0022-0302(02)74264-1

Brouwer E., 1965. Report of subcommittee on constants and factors. In Energy metabolism of farm animals. Third symposium on energy metabolism (ed. KL Blaxter), pp. 441-443. 
741 Charmley, E., Williams, S.R.O., Moate, P.J., Hegarty, R.S., Herd, R.M., Oddy, V.H., Reyenga, P., Staunton, K.M., Anderson, A., Hannah, M.C., 2016. A universal equation to predict methane production of forage-fed cattle in Australia. Anim. Prod. Sci. 56, 169-180. https://doi.org/10.1071/AN15365

Cottle, D.J., Eckard, R.J., 2018. Global beef cattle methane emissions: yield prediction by cluster and meta-analyses. Anim. Prod. Sci. 58, 2167-2177. https://doi.org/10.1071/AN17832

Dijkstra, J., van Zijderveld, S.M., Apajalahti, J.A., Bannink, A., Gerrits, W.J.J., Newbold, J.R., Perdok, H.B., Berends, H., 2011. Relationships between methane production and milk fatty acid profiles in dairy cattle. Anim. Feed Sci. Technol. 166-167, 590-595. https://doi.org/10.1016/j.anifeedsci.2011.04.042

Ellis, J.L., Kebreab, E., Odongo, N.E., McBride, B.W., Okine, E.K., France, J., 2007. Prediction of Methane Production from Dairy and Beef Cattle. J. Dairy Sci. 90, 34563466. https://doi.org/10.3168/jds.2006-675

Ellis, J.L., Kebreab, E., Odongo, N.E., Beauchemin, K., McGinn, S., Nkrumah, J.D., Moore, S.S., Christopherson, R., Murdoch, G.K., McBride, B.W., Okine, E.K., France, J., 2009. Modeling methane production from beef cattle using linear and nonlinear approaches. J. Anim. Sci. 87, 1334-1345. https://doi.org/10.2527/jas.2007-0725

Ellis, J.L., Bannink, A., France, J., Kebreab, E., Dijkstra, J., 2010. Evaluation of enteric methane prediction equations for dairy cows used in whole farm models. Glob. Chang. Biol. 16, 3246-3256. https://doi.org/10.1111/j.1365-2486.2010.02188.x

Escobar-Bahamondes, P., Oba, M., Beauchemin, K., 2017a. Universally applicable methane prediction equations for beef cattle fed high- or low-forage diets. Can. J. Anim. Sci. 94, CJAS-2016-0042. https://doi.org/10.1139/CJAS-2016-0042 
765 Escobar-Bahamondes, P., Oba, M., Beauchemin, K.A., 2017b. An evaluation of the accuracy and precision of methane prediction equations for beef cattle fed high-forage and highgrain diets. Animal 11, 68-77. https://doi.org/10.1017/S175173111600121X

Eugène, M., Benchaar, C., Chiquette, J., Massé, D., 2008. Meta-analysis on the effects of lipid supplementation on methane production of lactating dairy cows. Can. J. Anim. Sci. 88, 331-337. https://doi.org/10.4141/CJAS07112

FAO, 2010. Greenhouse Gas Emissions from the Dairy Sector. Food and Agriculture Organization of the United Nations, Rome, Italy.

Gerber, P., Vellinga, T., Opio, C., Steinfeld, H., 2011. Productivity gains and greenhouse gas emissions intensity in dairy systems. Livest. Sci., 139 (2011), pp. 100-108. https://doi.org/10.1016/j.livsci.2011.03.012

Giger-Reverdin, S., Morand-Fehr, P., Tran, G., 2003. Literature survey of the influence of dietary fat composition on methane production in dairy cattle. Livest. Prod. Sci. 82, 7379. https://doi.org/10.1016/S0301-6226(03)00002-2

Grainger, C., Beauchemin, K.A., 2011. Can enteric methane emissions from ruminants be lowered without lowering their production? Anim. Feed Sci. Technol. 166-167, 308320. https://doi.org/10.1016/j.anifeedsci.2011.04.021

Hammond, K.J., Crompton, L.A., Bannink, A., Dijkstra, J., Yáñez-Ruiz, D.R., O’Kiely, P., Kebreab, E., Eugène, M.A., Yu, Z., Shingfield, K.J., Schwarm, A., Hristov, A.N., Reynolds, C.K., 2016. Review of current in vivo measurement techniques for quantifying enteric methane emission from ruminants. Animal Feed Science and Technology 219, 13-30. https://doi.org/10.1016/j.anifeedsci.2016.05.018

Hindrichsen, I.K., Wettstein, H.R., Machmüller, A., Jörg, B., Kreuzer, M., 2005. Effect of the carbohydrate composition of feed concentrates on methane emission from dairy cows and their slurry. Environ. Monit. Assess. 107, 329-350. https://doi.org/10.1007/s10661- 
791 Hristov, A.N., Oh, J., Lee, C., Meinen, R., Montes, F., Ott, T., Firkins, J.L., Rotz, A., Dell, C.,

792

793

794 Adesogan, A.T., Yang, W., Tricarico, J., Kebreab, E., Dijkstra, J., Waghorn, G., Oosting S., 2013. Mitigation practices, in: Gerber, P.J., Henderson, B., and Makkar, H.P.S. (Eds), Mitigation of greenhouse gas emissions in livestock production: A review of technical options for non- $\mathrm{CO}_{2}$ emissions. FAO, Rome, pp. 9-60.

Hristov, A.N., Oh, J., Giallongo, F., Frederick, T.W., Harper, M.T., Weeks, H.L., Branco, A.F., Moate, P.J., Deighton, M.H., Williams, S.R.O., Kindermann, M., Duval, S. 2015. An inhibitor persistently decreased enteric methane emission from dairy cows with no negative effect on milk production. Proceedings of the National Academy of Science of the United States of America, 112, 10663-10688. https://doi.org/10.1073/pnas.1504124112

Hristov, A.N., Kebreab, E., Niu, M., Oh, J., Bannink, A., Bayat, A.R., Boland, T.B., Brito, A.F., Casper, D.P., Crompton, L.A., Dijkstra, J., Eugène, M., Garnsworthy, P.C., Haque, N., Hellwing, A.L.F., Huhtanen, P., Kreuzer, M., Kuhla, B., Lund, P., Madsen, J., Martin, C., Moate, P.J., Muetzel, S., Muñoz, C., Peiren, N., Powell, J.M., Reynolds, C.K., Schwarm, A., Shingfield, K.J., Storlien, T.M., Weisbjerg, M.R., Yáñez-Ruiz, D.R. Yu, Z., 2018. Symposium review: uncertainties in enteric methane inventories, measurement techniques, and prediction models. Journal of Dairy Science 101, 66556674. https://doi.org/10.3168/jds.2017-13536

IPCC (1997). Revised 1996 IPCC guidelines for national greenhouse gas inventories. Bracknell, UK: Intergovernmental Panel on Climate Change, IPCC/OECD/IEA. IPCC (2006). 2006 IPCC guidelines for national greenhouse gas inventories. IGES, Kanagawa, Japan: Intergovernmental Panel on Climate Change. Jayanegara, A., Leiber, F., Kreuzer, M., 2012. Meta-analysis of the relationship between 
dietary tannin level and methane formation in ruminants from in vivo and in vitro experiments. J. Anim. Physiol. Anim. Nutr. (Berl). 96, 365-375. https://doi.org/10.1111/j.1439-0396.2011.01172.x

Jung, H.G., Allen, M.S., 1995. Characteristics of plant cell walls affecting intake and digestibility of forages by ruminants. J. Anim. Sci. 73: 2774-2790. https://doi.org/10.2527/1995.7392774x

Kebreab, E., Clark, K., Wagner-Riddle, C., France, J., 2006. Methane and nitrous oxide emissions from Canadian animal agriculture: A review. Canadian Journal of Animal

Kebreab, E., Johnson, K.A., Archibeque, S.L., Pape,D., Wirth, T., 2008. Model for estimating 825 enteric methane emissions from United States dairy and feedlot cattle. Journal of Animal

Knapp, J.R., Laur, G.L., Vadas, P.A., Weiss, W.P., Tricarico, J.M., 2014. Invited review: Enteric methane in dairy cattle production: Quantifying the opportunities and impact of reducing emissions. J. Dairy Sci. 97, 3231-3261. https://doi.org/10.3168/jds.2013-7234

Lin, L.I.K., 1989. A Concordance Correlation Coefficient to Evaluate Reproducibility. Biometrics 45, 255-268. https://doi.org/10.2307/2532051

Martin, C Morgavi D. P. Doreau M., 2010. Methane mitigation in ruminants: from microbe to the farm scale. Animal, 4:3 351-365. https:// doi:10.1017/S1751731109990620

Mills, J.A.N., Kebreab, E., Yates, C.M., Crompton, L.A., Cammell, S.B., Dhanoa, M.S., Agnew, R.E., France, J., 2003. Alternative approaches to predicting methane emissions from dairy cows. J. Anim. Sci. 81, 3141-3150. https://doi.org/10.2527/2003.81123141x

Moate, P.J., Williams, S.R.O., Deighton, M. H., Hannah, M. C., Ribaux, B. E., Morris, G. L., Jacobs, J. L., Hill, J., Wales, W. J., 2017. Effects of feeding wheat or corn and of rumen fistulation on milk production and methane emissions of dairy cows. Animal Production 
Moate, P.J., Williams, S.R.O., Grainger, C., Hannah, M.C., Ponnampalam, E.N., Eckard, R.J., 2011. Influence of cold-pressed canola, brewers grains and hominy meal as dietary supplements suitable for reducing enteric methane emissions from lactating dairy cows. Anim. Feed Sci. Technol. 166-167, 254-264. https://doi.org/10.1016/j.anifeedsci.2011.04.069

Moe, P.W., Tyrrell, H.F., 1979. Methane production in dairy cows. Journal of Dairy Science, 62, 1583-1586. https://doi.org/10.3168/jds.S0022-0302(79)83465-7

Moraes, L.E., Strathe, A.B., Fadel, J.G., Casper, D.P., Kebreab, E., 2014. Prediction of enteric methane emissions from cattle. Glob. Chang. Biol. 20, 2140-2148. https://doi.org/10.1111/gcb.12471

Moriasi, J.G. Arnold, M.W. Van Liew, R.L. Bingner, R.D. Harmel, T.L. Veith, 2007. Model Evaluation Guidelines for Systematic Quantification of Accuracy in Watershed Simulations. Trans. ASABE 50, 885-900. https://doi.org/10.13031/2013.23153

Nielsen, N.I., Volden, H., Åkerlind, M., Brask, M., Hellwing, A.L.F., Storlien, T., Bertilsson, J., 2013. A prediction equation for enteric methane emission from dairy cows for use in NorFor. Acta Agric. Scand. A Anim. Sci. 63, 126-130. https://doi.org/10.1080/09064702.2013.851275

Niu, M., Kebreab, E., Hristov, A.N., Oh, J., Arndt, C., Bannink, A., Bayat, A.R., Brito, A.F., Boland, T., Casper, D., Crompton, L.A., Dijkstra, J., Eugène, M.A., Garnsworthy, P.C., Haque, M.N., Hellwing, A.L.F., Huhtanen, P., Kreuzer, M., Kuhla, B., Lund, P., Madsen, J., Martin, C., McClelland, S.C., McGee, M., Moate, P.J., Muetzel, S., Muñoz, C., O’Kiely, P., Peiren, N., Reynolds, C.K., Schwarm, A., Shingfield, K.J., Storlien, T.M., Weisbjerg, M.R., Yáñez-Ruiz, D.R., Yu, Z., 2018. Prediction of enteric methane production, yield, and intensity in dairy cattle using an intercontinental database. Glob. 
866 Patra, A.K., Lalhriatpuii, M., 2016. Development of statistical models for prediction of enteric methane emission from goats using nutrient composition and intake variables. Agric. Ecosyst. Environ. 215, 89-99. https://doi.org/10.1016/j.agee.2015.09.018

869

870

871

872

873

Patra, A.K., Lalhriatpuii, M., Debnath, B.C., 2016. Predicting enteric methane emission in sheep using linear and non-linear statistical models from dietary variables. Anim. Prod. Sci. 56, 574-584. https://doi.org/10.1071/AN15505

Ramin, M., Huhtanen, P., 2013. Development of equations for predicting methane emissions from ruminants. J. Dairy Sci. 96, 2476-2493. https://doi.org/10.3168/jds.2012-6095

Reynolds, C.K., Crompton, L.A., Mills, J.A.N., 2011. Improving the efficiency of energy utilization in cattle. Animal Production Science, 51, 6-12. ttps://doi.org/10.1071/AN10160

Ricci, P., Rooke, J. A., Nevison, I., Waterhouse,A., 2013. Methane emissions from beef and dairy cattle: quantifying the effect of physiological stage and diet characteristics. Journal of Animal Science 91, 5379-5389. doi:10.2527/jas.2013-6544

Robinson, P.H., Tamminga, S., Van Vuuren, A.M., 1986. Influence of declining level of feed intake and varying the proportion of starch in the concentrate on rumen fermentation in dairy cows. Livest. Prod. Sci., 15, pp. 173-189. https://doi.org/10.1016/0301$\underline{6226(86) 90026-6}$

Rotz, C.A., Corson, M.S., Chianese, D.S., Hafner, S.D., Jarvis, R., Coiner, C.U., 2011. The integrated farm system model-Reference Manual-Version 3.4188.

Sauvant, D., Giger-Reverdin, S., Serment lie, A., Broudiscou, L., 2011. Influences des regimes et de leur fermentation dans le rumen sur la production de methane par les ruminants. Prod. Anim. 24(5), 433-446.

Wilkerson, V.A., Casper D.P., Mertens, D.R., 1995. The prediction of methane production of 
Holstein cows by several equations. J. Dairy Sci. 78, 2402-2414. https://

891 doi:10.3168/jds.S0022-0302(95)76869-2

892 
Table 1. Variable summary statistics of the database for different regions and ruminant categories

\begin{tabular}{|c|c|c|c|c|c|c|c|c|c|c|c|c|c|c|c|}
\hline \multirow[b]{3}{*}{ Variables } & \multicolumn{5}{|c|}{ EUR } & \multicolumn{7}{|c|}{ US } & \multicolumn{3}{|c|}{$\mathrm{AU}$} \\
\hline & \multicolumn{5}{|c|}{ Dairy cattle } & \multicolumn{7}{|c|}{ Dairy cattle } & \multicolumn{3}{|c|}{ Dairy cattle } \\
\hline & $\mathrm{n}$ & Mean & SD & Min & $\operatorname{Max}$ & $\mathrm{n}$ & Mean & $\mathrm{SD}$ & Min & Max & $\mathrm{n}$ & Mean & $\mathrm{SD}$ & Min & $\operatorname{Max}$ \\
\hline $\mathrm{CH}_{4}$ emission & 1671 & 376 & 106 & 89.7 & 711 & 198 & 436 & 111 & 223 & 732 & 278 & 432 & 83.0 & 145 & 612 \\
\hline $\mathrm{CH}_{4}$ yield & 1671 & 20.9 & 4.18 & 6.53 & 41.7 & 198 & 16.2 & 4.27 & 8.28 & 32.5 & 106 & 23.1 & 3.46 & 11.9 & 30.0 \\
\hline $\mathrm{CH}_{4}$ intensity & 1441 & 14.1 & 4.48 & 3.22 & 59.3 & 198 & 11.1 & 3.84 & 4.68 & 31.7 & 94 & 24.1 & 7.82 & 13.0 & 66.2 \\
\hline $\mathrm{Ym}$ & 1599 & 6.28 & 1.23 & 2.14 & 11.3 & 198 & 4.91 & 1.27 & 2.55 & 9.79 & & & & & \\
\hline BW & 1617 & 619 & 77.8 & 365 & 956 & 195 & 652 & 75.1 & 487 & 863 & 158 & 577 & 64.7 & 416 & 906 \\
\hline FPCM & 1441 & 29.3 & 8.39 & 7.69 & 537 & 198 & 41.1 & 8.19 & 13.6 & 69.9 & 94 & 18.5 & 5.10 & 5.69 & 30.4 \\
\hline DMI & 1671 & 18.3 & 4.54 & 4.17 & 33.5 & 198 & 27.3 & 3.49 & 19.6 & 37.2 & 106 & 19.5 & 2.84 & 9.09 & 24.9 \\
\hline GEI & 1599 & 343 & 82.4 & 104 & 605 & 198 & 498 & 62.6 & 362 & 669 & & & & & \\
\hline forage & 1141 & 0.68 & 0.18 & 0.35 & 1.00 & 198 & 0.61 & 0.03 & 0.56 & 0.65 & 278 & 0.75 & 0.11 & 0.57 & 1.00 \\
\hline $\mathrm{CP}$ & 1570 & 165 & 30.7 & 81.0 & 274 & 198 & 165 & 6.11 & 152 & 177 & & & & & \\
\hline $\mathrm{EE}$ & 977 & 37.4 & 13.1 & 17.0 & 80.1 & 198 & 48.9 & 5.73 & 38.0 & 55.0 & 108 & 37.8 & 16.5 & 16.9 & 65 \\
\hline ASH & 1434 & 75.5 & 15.6 & 37.2 & 142 & 150 & 58.1 & 8.22 & 47.4 & 69.3 & & & & & \\
\hline NDF & 1376 & 377 & 108 & 134 & 697 & 198 & 297 & 22.0 & 273 & 332 & & & & & \\
\hline $\mathrm{ADF}$ & 1358 & 205 & 55.1 & 72.0 & 365 & 198 & 201 & 16.2 & 180 & 230 & & & & & \\
\hline STA & 1209 & 183 & 89.4 & 10.0 & 566 & 111 & 249 & 19.5 & 239 & 298 & & & & & \\
\hline $\mathrm{dOM}$ & 944 & 723 & 56.5 & 526 & 875 & 111 & 695 & 33.9 & 582 & 763 & & & & & \\
\hline $\mathrm{dNDF}$ & 675 & 624 & 110 & 198 & 906 & 111 & 455 & 60.7 & 266 & 560 & & & & & \\
\hline
\end{tabular}


Table 1 (continued)

\begin{tabular}{|c|c|c|c|c|c|c|c|c|c|c|c|c|c|c|c|}
\hline \multirow{2}{*}{ Variables } & \multicolumn{5}{|c|}{ EUR } & \multicolumn{5}{|c|}{ EUR } & \multicolumn{5}{|c|}{ EUR } \\
\hline & \multicolumn{5}{|c|}{ Beef cattle } & \multicolumn{5}{|c|}{ Sheep } & \multicolumn{5}{|c|}{ Goats } \\
\hline $\mathrm{CH}_{4}$ emission & 577 & 202 & 90.9 & 27.5 & 566 & 399 & 19.3 & 7.76 & 3.69 & 55.2 & 60 & 14.2 & 6.44 & 4.67 & 36.3 \\
\hline $\mathrm{CH}_{4}$ intensity & 363 & 210 & 108 & 37.1 & 845 & 12 & 59.3 & 22.0 & 20.2 & 90.0 & 24 & 13.7 & 7.38 & 3.33 & 27.2 \\
\hline Ym & 513 & 6.99 & 2.38 & 1.66 & 17.7 & 236 & 5.45 & 1.6 & 1.69 & 10.8 & 60 & 4.2 & 1.82 & 1.56 & 11 \\
\hline DMI & 577 & 8.76 & 2.11 & 3.05 & 14.1 & 399 & 0.99 & 0.3 & 0.33 & 1.93 & 60 & 1.03 & 0.28 & 0.4 & 1.5 \\
\hline GEI & 513 & 165 & 44.1 & 56.6 & 268 & 236 & 16.8 & 3.74 & 6.12 & 26.7 & 60 & 21.7 & 20.3 & 7.54 & 171 \\
\hline forage & 529 & 0.7 & 0.21 & 0.1 & 1 & 399 & 0.76 & 0.34 & 0 & 1 & 60 & 0.36 & 0.32 & 0 & 1 \\
\hline $\mathrm{CP}$ & 577 & 153 & 30.5 & 44 & 314 & 399 & 145 & 51.8 & 33.8 & 250 & 60 & 156 & 70 & 19.8 & 211 \\
\hline $\mathrm{EE}$ & 273 & 46.9 & 26.3 & 24.4 & 165 & 81 & 30.6 & 23.2 & 12.1 & 67 & 60 & 28.6 & 17.1 & 10.2 & 52.6 \\
\hline $\mathrm{dOM}$ & 137 & 745 & 55.6 & 563 & 820 & 342 & 645 & 75.6 & 455 & 831 & 36 & 757 & 52.5 & 654 & 837 \\
\hline $\mathrm{dNDF}$ & 302 & 509 & 147 & 157 & 874 & 354 & 598 & 117 & 266 & 853 & 36 & 558 & 64.8 & 438 & 718 \\
\hline
\end{tabular}

EUR = Europe; US = United States of America; $\mathrm{AU}=$ Australia; $\mathrm{CH}_{4}$ emissions = methane emissions $(\mathrm{g} / \mathrm{d}) ; \mathrm{CH}_{4}$ yield = methane emissions per $\mathrm{kg}$ of DMI;

$\mathrm{CH}_{4}$ intensity = methane emissions per $\mathrm{kg}$ of animal product $(\mathrm{kg}$ of fat and protein corrected milk for dairy cattle, sheep and goats; and kg of average daily gain for beef cattle); $\mathrm{Ym}=$ percentage of gross energy converted to $\mathrm{CH}_{4}(\%) ; \mathrm{BW}=$ body weight $(\mathrm{kg}) ; \mathrm{FPCM}=$ fat and protein corrected milk $(\mathrm{kg} / \mathrm{d})=$ milk yield $(\mathrm{kg} / \mathrm{d}) \times[0.337+0.116 \times$ fat $(\%)+0.06 \times$ protein $(\%)]$ according to Gerber et al. $(2011) ;$ DMI $=$ dry matter intake $(\mathrm{kg} / \mathrm{d}) ; \mathrm{GEI}=$ gross energy intake $(\mathrm{MJ} / \mathrm{d}) ;$ Forage $=$ forage proportion in the diet; $\mathrm{CP}=$ dietary crude protein content $(\mathrm{g} / \mathrm{kg} \mathrm{DM}) ; \mathrm{EE}=$ dietary ether extract content $(\mathrm{g} / \mathrm{kg} \mathrm{DM}) ; \mathrm{ASH}$ : dietary ash content (g/kg DM); NDF = dietary neutral detergent fiber content (g/kg DM); ADF = Acid Detergent Fiber (g/kg DM); STA = Starch (g/kg DM); dOM = digestibility of organic matter $(\mathrm{g} / \mathrm{kg} \mathrm{DM}) ; \mathrm{dNDF}=$ digestibility of $\mathrm{NDF}(\mathrm{g} / \mathrm{kg} \mathrm{DM}) ; \mathrm{n}=$ number of observations; $\mathrm{SD}$ = standard deviation; Min = minimum;

Max = maximum 
Table 2: List of models evaluated in this study among animal category and mitigation strategy.

\begin{tabular}{|c|c|c|c|c|c|}
\hline Source & Model & Prediction equation $\mathrm{CH}_{4}(\mathrm{~g} / \mathrm{d})=$ & $\begin{array}{l}\text { Animal } \\
\text { category } 1\end{array}$ & $\begin{array}{l}\text { Mitigation } \\
\text { strategy }^{2}\end{array}$ & Origin $^{3}$ \\
\hline Charmley et al. (2016) & Charmley_1 & $38+19.22 \times \mathrm{DMI}$ & Dairy & All diets & AU \\
\hline Charmley et al. (2016) & Charmley_2 & $(2.14+0.058 \times \mathrm{GEI}) / 0.05565$ & Dairy & All diets & $\mathrm{AU}$ \\
\hline Mills et al. (2003) & Mills_1 & $(5.93+0.92 \times \mathrm{DMI}) / 0.05565$ & Dairy & All diets & EUR \\
\hline Mills et al. (2003) & Mills_3 & $\left(56.27 \times\left(1-\exp ^{(-0.028 \times D M I)}\right)\right) / 0.05565$ & Dairy & All diets & EUR \\
\hline Nielsen et al. (2013) & Nielsen_1 & $(1.23 \times \mathrm{DMI}-0.145 \times \mathrm{FA}+0.012 \times \mathrm{NDF}) / 0.05565$ & Dairy & Lip, DQ & EUR \\
\hline Ellis et al. (2007) & Ellis_2 & $(3.14+2.11 \times \mathrm{NDFI}) / 0.05565$ & Dairy & DQ & US \\
\hline Ellis et al. (2007) & Ellis_3 & $\begin{array}{l}(2.16+0.493 \times \mathrm{DMI}-1.36 \times \mathrm{ADFI}+1.97 \times \mathrm{NDFI}) / \\
0.05565\end{array}$ & Dairy & DQ & US \\
\hline Moraes et al. (2014) & Moraes & $\begin{array}{l}(0.225+0.042 \times \mathrm{GEI}+0.0125 \times \mathrm{NDF}-0.0329 \times \\
\mathrm{EE}) / 0.05565\end{array}$ & Dairy & Lip, DQ & US \\
\hline Mills et al. (2003) & Mills_2 & $\begin{array}{l}(7.3+13.13 \times \mathrm{NI}+2.04 \times \mathrm{ADFI}+0.33 \times \\
\mathrm{STAI}) / 0.05565\end{array}$ & Dairy & DQ, STA & EUR \\
\hline $\begin{array}{l}\text { Escobar-Bahamondes et } \\
\text { al. (2017a) }\end{array}$ & Escobar & $\begin{array}{l}-35.0+0.08 \times \mathrm{BW}+120 \times \text { forage }-69.8 \times \mathrm{FA}^{3}+ \\
3.14 \times \mathrm{GEI}\end{array}$ & Beef & All diets & EUR, US, AU \\
\hline Yan et al. (2009) & Yan_1 & $((35.1 \times \mathrm{DMI})+14.7) \times 0.714$ & Beef & All diets & EUR \\
\hline Yan et al. (2009) & Yan_2 & $(1.959 \times \mathrm{GEI}+8.8)) \times 0.714$ & Beef & All diets & EUR \\
\hline Ellis et al. (2007) & Ellis_6 & $(-1.02+0.681 \times \mathrm{DMI}+4.81 \times$ forage $) / 0.05565$ & Beef & DQ & US \\
\hline Ellis et al. (2007) & Ellis_5 & $(5.58+0.848 \times \mathrm{NDFI}) / 0.05565$ & Beef & DQ & US \\
\hline Ellis et al. (2009) & Ellis_7 & $(4.72+1.13 \times \mathrm{STAI}) / 0.05565$ & Beef & STA & US \\
\hline Ellis et al. (2009) & Ellis_8 & $(-1.01+2.76 \times \mathrm{NDFI}+0.722 \times \mathrm{STAI}) / 0.05565$ & Beef & DQ, STA & US \\
\hline Ellis et al. (2009) & Ellis_9 & $(2.5-0.367 \times \mathrm{STAI} / \mathrm{ADFI}+0.766 \times \mathrm{DMI}) / 0.05565$ & Beef & DQ, STA & US \\
\hline Charmley et al. (2016) & Charmley_3 & $20.7 \times \mathrm{DMI}$ & Dairy and Beef & All diets & AU \\
\hline $\begin{array}{l}\text { Grainger and Beauchemin } \\
\text { (2011) }\end{array}$ & Grainger_3 & $(24.55-0.102 \times \mathrm{FA}) \times \mathrm{DMI}$ & Dairy and Beef & Lip & EUR, US, AU \\
\hline Moate et al. (2011) & Moate & $\left(\exp ^{(3.15-0.0035 \times \mathrm{FA})}\right) \times \mathrm{DMI}$ & Dairy and Beef & Lip & EUR, US \\
\hline IPCC $(1997)^{4}$ & IPCC_1997 & $(0.060 \times \mathrm{GEI}) / 0.05565$ & All categories & All diets & EUR, US, AU \\
\hline
\end{tabular}




\begin{tabular}{|c|c|c|c|c|c|}
\hline IPCC $(2006)^{4}$ & IPCC_2006 & $(0.065 \times \mathrm{GEI}) / 0.05565$ & All categories & All diets & EUR, US, AU \\
\hline $\begin{array}{l}\text { Ramin \& Huhtanen } \\
\text { (2013) }\end{array}$ & Ramin_2 & $\left(20+35.8 \times D M I-0.5 \times D^{D M I} I^{2}\right) \times 0.714$ & $\begin{array}{l}\text { Dairy, Beef and } \\
\text { Sheep }\end{array}$ & All diets & EUR, US, AU \\
\hline $\begin{array}{l}\text { Grainger and Beauchemin } \\
\text { (2011) }\end{array}$ & Grainger_1 & $(24.65-0.103 \times \mathrm{FA}) \times \mathrm{DMI}$ & All categories & Lip & EUR, US, AU \\
\hline $\begin{array}{l}\text { Grainger and Beauchemin } \\
\text { (2011) }\end{array}$ & Grainger_2 & $\left(26.5-(0.187 \times \mathrm{FA})+\left(0.0007 \times \mathrm{FA}^{2}\right)\right) \times \mathrm{DMI}$ & All categories & Lip & EUR, US, AU \\
\hline $\begin{array}{l}\text { Ramin \& Huhtanen } \\
\text { (2013) }\end{array}$ & Ramin_1 & $\begin{array}{l}(49.7-0.63 \times \mathrm{DMI} / \mathrm{BW}+0.59 \times \mathrm{dGE}-0.2 \times \mathrm{EE}) \times \\
\mathrm{GEI} / 0.0555\end{array}$ & $\begin{array}{l}\text { Dairy, Beef and } \\
\text { Sheep }\end{array}$ & Lip, DQ & EUR, US, AU \\
\hline $\begin{array}{l}\text { Ramin \& Huhtanen } \\
\text { (2013) }\end{array}$ & Ramin_3 & $\begin{array}{l}(-0.6-0.7 \times \mathrm{DMI} / \mathrm{BW}+0.076 \times \mathrm{dOM}-0.13 \times \mathrm{EE}+ \\
0.046 \times \mathrm{NDF}+0.044 \times \mathrm{NFC}) \times \mathrm{GEI} / 0.0555 \\
{\left[45.42-6.66 \times \mathrm{DMI} / \mathrm{BW}+0.75 \times \mathrm{DMI} / \mathrm{BW}^{2}+\right.}\end{array}$ & $\begin{array}{l}\text { Dairy, Beef and } \\
\text { Sheep }\end{array}$ & DQ, STA & EUR, US, AU \\
\hline Sauvant et al. (2016) & Sauvant_1 & $\begin{array}{l}19.65 \times \mathrm{pCO}-35.0 \times \mathrm{pCO}^{2}-2.69 \times(\mathrm{DMI} / \mathrm{BW}) \times \\
\mathrm{pCO}] \times \mathrm{OMI} \times \mathrm{dOM}\end{array}$ & All categories & DQ, STA & EUR, US, AU \\
\hline Sauvant et al. (2016) & Sauvant_2 & $(7.14+0.22 * \mathrm{dOM}) * \mathrm{DMI}$ & All categories & DQ, STA & EUR, US, AU \\
\hline Patra et al. (2016) & Patra_1 & $(0.223+0.876 \times \mathrm{DMI}) / 0.05565$ & Sheep & All diets & \\
\hline Patra et al. (2016) & Patra_2 & $(0.208+0.049 \times \mathrm{GEI}) / 0.05565$ & Sheep & All diets & EUR, US, AU \\
\hline Patra et al. (2016) & Patra_3 & $(0.289+0.067 \times \mathrm{DEI}) / 0.05565$ & Sheep & All diets & EUR, US, AU \\
\hline $\begin{array}{l}\text { Patra \& Lalhriatpuii } \\
\text { (2016) }\end{array}$ & Patra_4 & $(0.296+0.569 \times \mathrm{DMI}) / 0.05565$ & Goats & All diets & EUR, US, AU \\
\hline $\begin{array}{l}\text { Patra \& Lalhriatpuii } \\
\text { (2016) }\end{array}$ & Patra_5 & $(0.507+0.573 \times \mathrm{DMI}-0.00074 \times \mathrm{ADF}) / 0.05565$ & Goats & All diets & EUR, US, AU \\
\hline $\begin{array}{l}\text { Patra \& Lalhriatpuii } \\
\text { (2016) }\end{array}$ & Patra_6 & $(1.29-0.0011 \times \mathrm{NDF}) / 0.05565$ & Goats & All diets & EUR, US, AU \\
\hline FAO 2010 & FAO 2010 & $((9.75-0.005 \times \mathrm{DMD}) \times \mathrm{GEI}) / 0.05565$ & Goats & All diets & - \\
\hline
\end{tabular}

$\mathrm{DMI}=$ dry matter intake $(\mathrm{kg} / \mathrm{d}), \mathrm{GEI}=$ gross energy intake $(\mathrm{MJ} / \mathrm{d}), \mathrm{FA}=$ dietary fatty acids $(\mathrm{g} / \mathrm{kg} \mathrm{DM}), \mathrm{NDF}=$ dietary neutral detergent fiber $(\mathrm{g} / \mathrm{kg}$ $\mathrm{DM}), \mathrm{NDFI}=\mathrm{NDF}$ intake $(\mathrm{kg} / \mathrm{d}), \mathrm{ADF}=$ dietary acid detergent fiber $(\mathrm{g} / \mathrm{kg} \mathrm{DM}), \mathrm{ADFI}=\mathrm{ADF}$ intake $(\mathrm{kg} / \mathrm{d}), \mathrm{EE}=$ dietary extract ether $(\mathrm{g} / \mathrm{kg} \mathrm{DM})$, 
$\mathrm{EEI}=\mathrm{EE}$ intake $(\mathrm{kg} / \mathrm{d}), \mathrm{BW}=$ body weight $(\mathrm{kg})$, forage $=$ forage proportion in the diet, $\mathrm{NI}=$ nitrogen intake $(\mathrm{kg} / \mathrm{d}), \mathrm{STA}=\operatorname{dietary} \mathrm{starch}(\mathrm{g} / \mathrm{kg}$ $\mathrm{DM}), \mathrm{STAI}=\mathrm{STA}$ intake $(\mathrm{kg} / \mathrm{d}), \mathrm{dGE}=$ digestibility of gross energy $(\mathrm{g} / \mathrm{kg} \mathrm{DM}), \mathrm{dOM}=$ digestibility of organic matter $(\mathrm{g} / \mathrm{kg} \mathrm{DM}), \mathrm{NFC}=$ non fibrous carbohydrates $(\mathrm{g} / \mathrm{kg} \mathrm{DM}), \mathrm{pCO}=$ concentrate proportion in the diet, OMI = organic matter intake $(\mathrm{kg} / \mathrm{d})$, DEI = digestible energy intake $(\mathrm{MJ} / \mathrm{d})$.

${ }^{1}$ Animal category in which model is applied: Dairy = Dairy cattle, Beef $=$ Beef cattle, All categories $=$ dairy and beef cattle and small ruminants ${ }^{2}$ Mitigation strategy: All diets = Performance using all data of corresponding animal category, Lip = lipid supplementation, DQ = Diet quality, STA $=$ Starch content. ${ }^{3}$ origin of data used in the model development: EUR $=$ Europe, US $=$ United States of America, AU = Australia. ${ }^{4}$ IPCC_1997 and IPCC_2006 are used for dairy cattle, beef cattle with forage proportion in the diet $<0.90$ and mature sheep $(>1$ year). For feedlot cattle (concentrate proportion $>0.90$ ) and young sheep (<1 year) Ym values of 3 and $4.5 \%$ were used. 
Table 3. Evaluation of the performance of $\mathrm{CH}_{4}$ emissions (g/d) prediction models for dairy cattle (ranked by RSR)

\begin{tabular}{|c|c|c|c|c|c|c|c|c|c|c|}
\hline Rank & Model & $\mathrm{n}$ & $\operatorname{RMSPE}(\mathrm{g} / \mathrm{d})$ & $\begin{array}{c}\text { RMSPE } \\
\%\end{array}$ & $\begin{array}{c}\text { ECT } \\
\%\end{array}$ & $\begin{array}{c}\mathrm{ER} \\
\%\end{array}$ & $\begin{array}{c}\text { ED } \\
\%\end{array}$ & $\mathrm{CCC}$ & $r$ & RSR \\
\hline 1 & Ramin_1 & 463 & 61.0 & 15.6 & 0.70 & 2.90 & 96.4 & 0.75 & 0.76 & 0.66 \\
\hline 2 & Ramin_2 & 1958 & 82.1 & 21.2 & 6.30 & 3.30 & 90.4 & 0.57 & 0.69 & 0.76 \\
\hline 3 & Mills_3 & 1975 & 84.3 & 21.8 & 11.7 & 1.50 & 86.8 & 0.64 & 0.69 & 0.78 \\
\hline 4 & IPCC_1997 & 1797 & 82.3 & 21.2 & 0.10 & 12.8 & 87.1 & 0.68 & 0.68 & 0.79 \\
\hline 5 & Ellis_3 & 1034 & 88.7 & 22.7 & 11.5 & 0.80 & 87.7 & 0.60 & 0.66 & 0.80 \\
\hline 6 & Charmley_2 & 1797 & 84.5 & 21.8 & 7.60 & 9.60 & 82.8 & 0.66 & 0.68 & 0.81 \\
\hline 7 & Charmley_1 & 1869 & 87.0 & 22.8 & 8.10 & 9.80 & 82.0 & 0.66 & 0.68 & 0.81 \\
\hline 8 & Charmley_3 & 1869 & 87.6 & 22.9 & 3.00 & 16.0 & 81.0 & 0.67 & 0.68 & 0.81 \\
\hline 9 & Mills_2 & 1320 & 72.5 & 17.8 & 4.00 & 4.40 & 91.6 & 0.59 & 0.62 & 0.82 \\
\hline 10 & Mills_1 & 1975 & 89.3 & 23.1 & 18.4 & 1.80 & 79.8 & 0.61 & 0.68 & 0.83 \\
\hline 11 & Ramin_3 & 626 & 80.0 & 20.5 & 5.40 & 8.10 & 86.5 & 0.61 & 0.63 & 0.84 \\
\hline 12 & Sauvant_1 & 967 & 93.5 & 27.4 & 12.5 & 9.90 & 77.6 & 0.63 & 0.66 & 0.85 \\
\hline 13 & IPCC_2006 & 1797 & 90.8 & 23.4 & 11.0 & 17.4 & 71.6 & 0.65 & 0.68 & 0.87 \\
\hline
\end{tabular}

Rank = rank of the performance based on the RSR, $n=$ number of observations; RMSPE = Square root of the mean square prediction error,

expressed in $\mathrm{g} / \mathrm{d}$ and RMSPE\% as a percentage of methane emissions mean; ECT\% = error due to central tendency expressed as a percentage of

RMSPE; ER\% = error due to deviation of the regression slope expressed as a percentage of RMSPE; ED\% = error due to the disturbance

expressed as percentage of RMSPE; CCC = concordance correlation coefficient; $r=$ correlation coefficient; RSR = RMSPE to standard deviation

of observed values ratio. 
Table 4. Evaluation of the performance of $\mathrm{CH}_{4}$ emissions (g/d) prediction models for dairy cattle fed lipid supplements, diets with different contents of NDF and STA, and diets of different quality (ranked by RSR).

\begin{tabular}{|c|c|c|c|c|c|c|c|c|c|c|c|c|}
\hline \multicolumn{2}{|l|}{$\begin{array}{l}\text { Mitigation } \\
\text { strategy }\end{array}$} & Rank & Model & $\mathrm{n}$ & $\begin{array}{l}\text { RMSPE } \\
(\mathrm{g} / \mathrm{d}) \\
64.0\end{array}$ & $\begin{array}{l}\text { RMSPE } \\
\% \\
17.1\end{array}$ & $\begin{array}{l}\text { ECT } \\
\% \\
7.68\end{array}$ & $\begin{array}{l}\text { ER } \\
\% \\
15.2\end{array}$ & $\begin{array}{l}\text { ED } \\
\% \\
77.1\end{array}$ & $\frac{\mathrm{CCC}}{0.71}$ & $\begin{array}{l}r \\
0.73\end{array}$ & $\begin{array}{l}\text { RSR } \\
0.78\end{array}$ \\
\hline \multirow{7}{*}{ supplementation } & \multirow{4}{*}{$\begin{array}{l}\text { The low-EE } \\
\text { diets } \\
(\text { mean } 30.4 \mathrm{~g} / \mathrm{kg} \\
\text { DM) }\end{array}$} & 2 & IPCC_2006 & 685 & 65.7 & 17.6 & 3.33 & 23.7 & 73.0 & 0.71 & 0.73 & 0.80 \\
\hline & & 4 & Grainger_3 & 609 & 72.4 & 19.6 & 23.7 & 16.6 & 59.7 & 0.67 & 0.73 & 0.89 \\
\hline & & 5 & Grainger_1 & 609 & 73.2 & 19.8 & 25.1 & 16.5 & 58.4 & 0.66 & 0.73 & 0.90 \\
\hline & & 6 & Nielsen_1 & 557 & 75.0 & 19.9 & 43.8 & 7.89 & 48.3 & 0.64 & 0.76 & 0.93 \\
\hline & \multirow{3}{*}{$\begin{array}{l}\text { The high-EE } \\
\text { diets } \\
(\text { mean } 51.7 \mathrm{~g} / \mathrm{kg} \\
\text { DM) }\end{array}$} & 3 & Moraes & 490 & 95.3 & 22.9 & 27.8 & 0.87 & 71.3 & 0.47 & 0.59 & 0.95 \\
\hline & & 4 & IPCC_1997 & 490 & 105 & 25.3 & 11.4 & 22.9 & 65.6 & 0.49 & 0.52 & 1.05 \\
\hline & & 5 & IPCC_2006 & 490 & 127 & 30.5 & 33.3 & 21.6 & 45.1 & 0.42 & 0.52 & 1.27 \\
\hline \multirow{5}{*}{$\begin{array}{l}\text { Diet quality by } \\
\text { NDF content }\end{array}$} & \multirow{3}{*}{$\begin{array}{l}\text { The low-NDF } \\
\text { diets (mean } 285 \\
\text { g/kg DM) }\end{array}$} & 1 & Ramin_1 & 67 & 41.9 & 10.1 & 2.31 & 1.96 & 95.7 & 0.88 & 0.88 & 0.48 \\
\hline & & 2 & Ellis_3 & 414 & 89.9 & 21.7 & 6.78 & 5.10 & 88.1 & 0.40 & 0.45 & 0.95 \\
\hline & & 3 & IPCC_1997 & 701 & 96.1 & 23.7 & 13.6 & 22.8 & 63.7 & 0.49 & 0.53 & 1.06 \\
\hline & \multirow{2}{*}{$\begin{array}{l}\text { The high-NDF } \\
\text { diets (mean } 433 \\
\text { g/kg) DM) }\end{array}$} & 5 & Ramin_3 & 381 & 60.7 & 15.1 & 4.11 & 1.91 & 94.0 & 0.77 & 0.79 & 0.63 \\
\hline & & 6 & IPCC_1997 & 817 & 67.0 & 16.9 & 36.5 & 2.73 & 60.8 & 0.78 & 0.85 & 0.68 \\
\hline \multirow[t]{6}{*}{ STA content } & \multirow{4}{*}{$\begin{array}{l}\text { The low-STA } \\
\text { diets } \\
(\text { mean } 56.1 \mathrm{~g} / \mathrm{kg} \\
\text { DM) }\end{array}$} & 1 & IPCC_2006 & 217 & 48.4 & 13.3 & 4.50 & 8.60 & 86.9 & 0.65 & 0.67 & 0.80 \\
\hline & & 2 & Mills_2 & 217 & 53.2 & 14.6 & 14.5 & 1.42 & 84.1 & 0.52 & 0.59 & 0.87 \\
\hline & & 3 & Ramin_3 & 144 & 40.3 & 11.9 & 26.7 & 10.4 & 63.0 & 0.58 & 0.65 & 0.95 \\
\hline & & 4 & IPCC_1997 & 217 & 59.5 & 16.4 & 39.7 & 2.82 & 57.5 & 0.54 & 0.67 & 0.98 \\
\hline & The high-STA & 1 & Mills_2 & 1103 & 75.7 & 18.2 & 3.13 & 5.39 & 91.5 & 0.58 & 0.60 & 0.84 \\
\hline & diets & 2 & Ramin_3 & 446 & 90.2 & 22.0 & 4.05 & 8.41 & 87.5 & 0.54 & 0.56 & 0.88 \\
\hline
\end{tabular}




\begin{tabular}{|c|c|c|c|c|c|c|c|c|c|c|c|c|}
\hline \multirow{9}{*}{$\begin{array}{l}\text { Diet quality by } \\
\text { dOM }\end{array}$} & $\begin{array}{l}\text { (mean } 215 \mathrm{~g} / \mathrm{kg} \\
\text { DM) }\end{array}$ & $\begin{array}{l}3 \\
4\end{array}$ & $\begin{array}{l}\text { IPCC_1997 } \\
\text { IPCC_2006 }\end{array}$ & $\begin{array}{l}1102 \\
1102\end{array}$ & $\begin{array}{l}83.9 \\
93.6\end{array}$ & $\begin{array}{l}20.2 \\
22.6\end{array}$ & $\begin{array}{l}0.05 \\
12.1\end{array}$ & $\begin{array}{l}22.8 \\
26.0\end{array}$ & $\begin{array}{l}77.2 \\
61.9\end{array}$ & $\begin{array}{l}0.58 \\
0.54\end{array}$ & $\begin{array}{l}0.58 \\
0.58 \\
\end{array}$ & $\begin{array}{l}0.93 \\
1.04 \\
\end{array}$ \\
\hline & \multirow{4}{*}{$\begin{array}{l}\text { The low-dOM } \\
\text { diets (mean } 679 \\
\text { g/kg DM) }\end{array}$} & 1 & Ellis_3 & 323 & 82.4 & 21.8 & 0.01 & 0.31 & 99.7 & 0.72 & 0.76 & 0.65 \\
\hline & & 2 & Ramin_1 & 199 & 69.5 & 17.2 & 15.2 & 4.82 & 80.0 & 0.72 & 0.76 & 0.73 \\
\hline & & 3 & Ellis_2 & 323 & 103 & 27.2 & 13.4 & 2.93 & 83.7 & 0.52 & 0.67 & 0.81 \\
\hline & & 4 & Ramin_3 & 265 & 87.1 & 20.7 & 5.46 & 9.66 & 84.9 & 0.60 & 0.62 & 0.85 \\
\hline & \multirow{4}{*}{$\begin{array}{l}\text { The high-dOM } \\
\text { diets (mean } 767 \\
\text { g/kg DM) }\end{array}$} & 1 & Ellis_3 & 290 & 55.6 & 15.6 & 1.02 & 0.01 & 99.0 & 0.84 & 0.85 & 0.53 \\
\hline & & 2 & Ramin_1 & 230 & 54.9 & 14.6 & 2.73 & 0.18 & 97.1 & 0.79 & 0.81 & 0.60 \\
\hline & & 3 & Ellis_2 & 290 & 73.3 & 20.6 & 25.0 & 5.55 & 69.5 & 0.68 & 0.81 & 0.70 \\
\hline & & 4 & IPCC_1997 & 479 & 71.1 & 20.5 & 2.85 & 17.6 & 79.6 & 0.72 & 0.72 & 0.77 \\
\hline \multirow{10}{*}{$\begin{array}{l}\text { Diet quality by } \\
\text { dNDF }\end{array}$} & \multirow{5}{*}{$\begin{array}{l}\text { The low-dNDF } \\
\text { Diets } \\
\text { (mean } 504 \mathrm{~g} / \mathrm{kg} \\
\text { DM) }\end{array}$} & 1 & Ellis_3 & 337 & 78.8 & 19.9 & 1.39 & 0.02 & 98.6 & 0.71 & 0.74 & 0.67 \\
\hline & & 2 & Ramin_1 & 179 & 71.6 & 16.7 & 17.3 & 7.14 & 75.5 & 0.70 & 0.74 & 0.78 \\
\hline & & 3 & Ellis_2 & 337 & 98.7 & 24.9 & 34.3 & 5.29 & 60.5 & 0.54 & 0.75 & 0.84 \\
\hline & & 4 & Ramin_3 & 278 & 88.8 & 20.9 & 2.31 & 12.7 & 85.0 & 0.58 & 0.59 & 0.88 \\
\hline & & 5 & Mills_2 & 352 & 103 & 25.1 & 19.9 & 7.70 & 72.4 & 0.47 & 0.53 & 0.99 \\
\hline & \multirow{5}{*}{$\begin{array}{l}\text { The high-dNDF } \\
\text { diets } \\
\text { (mean } 700 \mathrm{~g} / \mathrm{kg} \\
\text { DM) }\end{array}$} & 1 & Ramin_3 & 244 & 50.0 & 13.3 & 14.2 & 2.85 & 83.0 & 0.82 & 0.84 & 0.59 \\
\hline & & 2 & Ellis_3 & 307 & 62.6 & 18.4 & 0.31 & 0.00 & 99.7 & 0.78 & 0.80 & 0.59 \\
\hline & & 3 & Mills_2 & 287 & 52.2 & 13.5 & 24.6 & 0.78 & 74.6 & 0.75 & 0.83 & 0.65 \\
\hline & & 4 & IPCC_2006 & 345 & 59.2 & 16.2 & 1.03 & 26.0 & 73.0 & 0.82 & 0.83 & 0.65 \\
\hline & & 5 & Ramin_1 & 215 & 54.5 & 14.3 & 1.12 & 3.07 & 95.8 & 0.76 & 0.77 & 0.66 \\
\hline
\end{tabular}

$\mathrm{EE}=$ dietary ether extract $(\mathrm{g} / \mathrm{kg} \mathrm{DM}), \mathrm{NDF}=$ neutral detergent fiber $(\mathrm{g} / \mathrm{kg} \mathrm{DM}), \mathrm{STA}=$ dietary starch $(\mathrm{g} / \mathrm{kg} \mathrm{DM})$, dOM = digestibility of organic

matter $(\mathrm{g} / \mathrm{kg} \mathrm{DM}), \mathrm{dNDF}=$ digestibility of NDF ( $/ \mathrm{kg} \mathrm{DM})$, Rank = rank of the performance based on the RSR, $\mathrm{n}=$ number of observations;

$\mathrm{RMSPE}=$ Square root of the mean square prediction error, expressed in $\mathrm{g} / \mathrm{d}$ and RMSPE\% as a percentage of methane emissions means; ECT\% $=$

error due to central tendency expressed as a percentage of RMSPE; ER\% = error due to deviation of the regression slope expressed as a percentage

of RMSPE; ED $\%=$ error due to the disturbance expressed as percentage of RMSPE; CCC = concordance correlation coefficient; $r=$ correlation

coefficient; RSR = RMSPE to standard deviation of observed values ratio. 
Table 5. Evaluation of the performance of $\mathrm{CH}_{4}$ emissions (g/d) prediction models for beef cattle (ranked by RSR).

\begin{tabular}{lllcccccccc}
\hline Rank & Model & $\mathrm{n}$ & $\begin{array}{c}\text { RMSPE } \\
(\mathrm{g} / \mathrm{d})\end{array}$ & $\begin{array}{c}\text { RMSPE } \\
\%\end{array}$ & $\begin{array}{c}\text { ECT } \\
\%\end{array}$ & $\begin{array}{c}\text { ER } \\
\%\end{array}$ & $\begin{array}{c}\text { ED } \\
\%\end{array}$ & CCC & $r$ & $\begin{array}{c}\text { RSR } \\
2\end{array}$ \\
\hline 1 & Escobar & 161 & 66.1 & 27.2 & 0.49 & 5.94 & 93.6 & 0.40 & 0.60 & 0.83 \\
2 & Ramin_2 & 419 & 75.3 & 33.3 & 0.77 & 1.92 & 97.3 & 0.42 & 0.56 & 0.84 \\
3 & Yan_1 & 419 & 76.3 & 33.8 & 5.07 & 0.06 & 94.9 & 0.48 & 0.56 & 0.85 \\
4 & Yan_2 & 403 & 78.0 & 34.0 & 9.29 & 0.77 & 89.9 & 0.49 & 0.57 & 0.87 \\
5 & IPCC_2006 & 380 & 76.6 & 32.7 & 15.0 & 0.43 & 84.6 & 0.46 & 0.60 & 0.87 \\
6 & Charmley_3 & 419 & 82.2 & 36.4 & 17.5 & 0.80 & 81.7 & 0.39 & 0.56 & 0.91 \\
7 & IPCC_1997 & 403 & 84.2 & 36.7 & 22.1 & 0.61 & 77.3 & 0.39 & 0.57 & 0.93 \\
8 & Grainger_2 & 177 & 77.1 & 32.9 & 18.6 & 0.43 & 81.0 & 0.40 & 0.52 & 0.95 \\
9 & Grainger_1 & 177 & 78.7 & 33.6 & 21.8 & 0.06 & 78.1 & 0.37 & 0.52 & 0.97 \\
\hline
\end{tabular}

Rank = rank of the performance based on the RSR, $n=$ number of observations; RMSPE = Square root of the mean square prediction error,

expressed in $\mathrm{g} / \mathrm{d}$ and RMSPE\% as a percentage of methane emissions means; ECT\% = error due to central tendency expressed as a percentage of

RMSPE; ER\% = error due to deviation of the regression slope expressed as a percentage of RMSPE; ED\% = error due to the disturbance expressed as percentage of RMSPE; CCC $=$ concordance correlation coefficient $r=$ correlation coefficient RSR $=$ RMSPE to standard deviation of observed values ratio. 
Table 6. Evaluation of the performance of $\mathrm{CH}_{4}$ emissions (g/d) prediction models for beef cattle fed lipid supplements or diets with different contents of NDF and STA and diets of different quality (ranked by RSR).

\begin{tabular}{|c|c|c|c|c|c|c|c|c|c|c|c|c|}
\hline $\begin{array}{l}\text { Mitigation } \\
\text { strategy }\end{array}$ & & Rank & Model & $\mathrm{n}$ & $\begin{array}{l}\text { RMSPE } \\
(\mathrm{g} / \mathrm{d})\end{array}$ & $\begin{array}{l}\text { RMSPE } \\
\%\end{array}$ & $\begin{array}{l}\text { ECT } \\
\%\end{array}$ & $\begin{array}{l}\text { ER } \\
\%\end{array}$ & $\begin{array}{l}\mathrm{ED} \\
\%\end{array}$ & $\mathrm{CCC}$ & $r$ & RSR \\
\hline \multirow{12}{*}{$\begin{array}{l}\text { Lipid } \\
\text { supplementation }\end{array}$} & \multirow{6}{*}{$\begin{array}{l}\text { The low-EE } \\
\text { diets (mean } 25.3 \mathrm{~g} / \mathrm{kg} \\
\text { DM) }\end{array}$} & 1 & Escobar & 80 & 68.8 & 26.3 & 2.43 & 6.07 & 91.5 & 0.40 & 0.59 & 0.84 \\
\hline & & 2 & Grainger_2 & 80 & 73.5 & 28.1 & 12.1 & 0.04 & 87.9 & 0.41 & 0.54 & 0.89 \\
\hline & & 3 & Grainger_1 & 80 & 76.8 & 29.4 & 19.3 & 0.14 & 80.5 & 0.38 & 0.54 & 0.93 \\
\hline & & 4 & Grainger_3 & 80 & 77.2 & 29.5 & 20.1 & 0.16 & 79.7 & 0.38 & 0.54 & 0.94 \\
\hline & & 5 & IPCC_2006 & 95 & 78.0 & 31.0 & 33.2 & 0.17 & 66.6 & 0.40 & 0.59 & 0.98 \\
\hline & & 6 & IPCC__1997 & 95 & 88.4 & 35.1 & 47.5 & 0.56 & 52.0 & 0.33 & 0.59 & 1.11 \\
\hline & \multirow{6}{*}{$\begin{array}{l}\text { The high-EE } \\
\text { diets (mean } 58.4 \mathrm{~g} / \mathrm{kg} \\
\text { DM) }\end{array}$} & 1 & Escobar & 81 & 63.3 & 28.1 & 0.05 & 3.99 & 96.0 & 0.33 & 0.53 & 0.86 \\
\hline & & 2 & Grainger_2 & 145 & 72.1 & 39.0 & 3.18 & 0.08 & 96.7 & 0.16 & 0.29 & 0.97 \\
\hline & & 3 & Grainger_1 & 145 & 73.0 & 39.5 & 2.49 & 0.58 & 96.9 & 0.13 & 0.24 & 0.98 \\
\hline & & 4 & Grainger_3 & 145 & 73.1 & 39.5 & 2.72 & 0.58 & 96.7 & 0.13 & 0.24 & 0.98 \\
\hline & & 5 & IPCC_2006 & 114 & 72.1 & 33.1 & 31.3 & 0.63 & 68.1 & 0.24 & 0.40 & 1.11 \\
\hline & & 6 & IPCC__1997 & 114 & 80.4 & 36.9 & 45.1 & 0.17 & 54.8 & 0.19 & 0.40 & 1.24 \\
\hline \multirow{8}{*}{$\begin{array}{l}\text { Diet quality by } \\
\text { NDF content }\end{array}$} & \multirow{4}{*}{$\begin{array}{l}\text { The low-NDF diets } \\
\text { (mean } 248 \text { g/kg DM) }\end{array}$} & 1 & Escobar & 79 & 62.6 & 27.6 & 0.09 & 4.21 & 95.7 & 0.40 & 0.55 & 0.86 \\
\hline & & 2 & IPCC_2006 & 173 & 79.5 & 38.7 & 3.12 & 0.34 & 96.5 & 0.38 & 0.47 & 0.89 \\
\hline & & 3 & IPCC_1997 & 173 & 83.2 & 40.5 & 11.9 & 0.02 & 88.0 & 0.34 & 0.47 & 0.94 \\
\hline & & 4 & Ellis_6 & 173 & 95.5 & 46.4 & 42.2 & 7.03 & 50.8 & 0.28 & 0.64 & 1.07 \\
\hline & \multirow{4}{*}{$\begin{array}{l}\text { The high-NDF diets } \\
\text { (mean } 425 \text { g/kg DM) }\end{array}$} & 1 & Escobar & 78 & 66.2 & 25.9 & 2.07 & 5.56 & 92.4 & 0.44 & 0.61 & 0.84 \\
\hline & & 2 & IPCC_2006 & 230 & 76.5 & 31.0 & 16.6 & 0.40 & 83.0 & 0.45 & 0.60 & 0.88 \\
\hline & & 3 & IPCC_1997 & 230 & 84.9 & 34.4 & 31.6 & 0.99 & 67.4 & 0.38 & 0.60 & 0.98 \\
\hline & & 4 & Ellis_6 & 230 & 107 & 43.3 & 51.6 & 2.52 & 45.9 & 0.20 & 0.55 & 1.23 \\
\hline \multirow[t]{5}{*}{ STA content } & \multirow{4}{*}{$\begin{array}{l}\text { The low-STA } \\
\text { Diets (mean } 60 \mathrm{~g} / \mathrm{kg} \\
\text { DM) }\end{array}$} & 1 & IPCC_2006 & 128 & 85.5 & 34.9 & 30.4 & 0.74 & 68.9 & 0.36 & 0.57 & 0.99 \\
\hline & & 2 & IPCC_1997 & 128 & 95.1 & 38.8 & 43.1 & 1.24 & 55.7 & 0.30 & 0.57 & 1.10 \\
\hline & & 3 & Ellis_8 & 128 & 101 & 41.1 & 43.3 & 0.25 & 56.4 & 0.23 & 0.49 & 1.16 \\
\hline & & 4 & Ellis_7 & 128 & 172 & 70.0 & 76.0 & 6.26 & 17.7 & 0.01 & 0.55 & 1.98 \\
\hline & The high-STA & 1 & IPCC_2006 & 289 & 74.4 & 32.1 & 10.5 & 1.37 & 88.1 & 0.38 & 0.47 & 0.94 \\
\hline
\end{tabular}




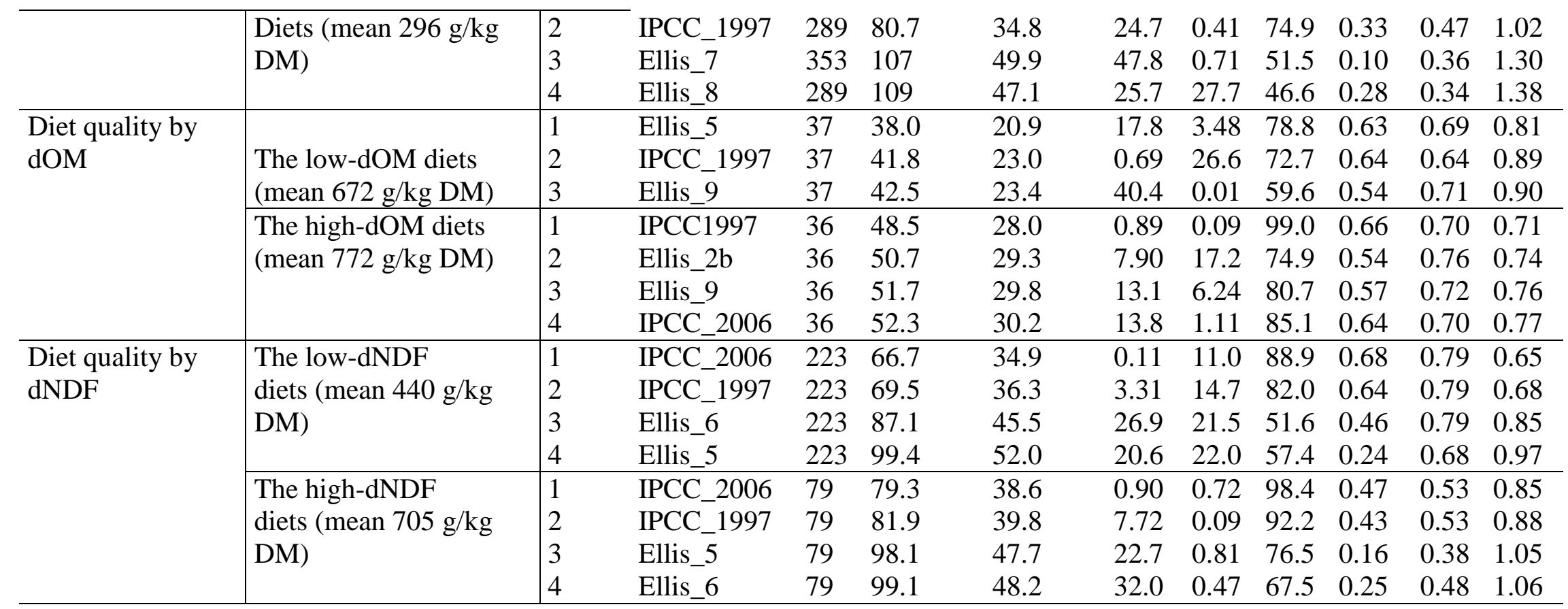

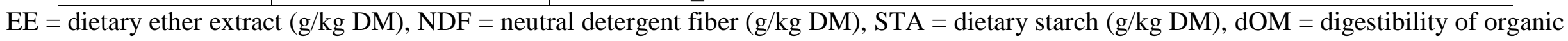
matter $(\mathrm{g} / \mathrm{kg} \mathrm{DM}), \mathrm{dNDF}=$ digestibility of NDF $(\mathrm{g} / \mathrm{kg} \mathrm{DM})$, Rank = rank of the performance based on the RSR, $\mathrm{n}=$ number of observations; RMSPE $=$ Square root of the mean square prediction error, expressed in $\mathrm{g} / \mathrm{d}$ and RMSPE\% as a percentage of methane emissions means; $\mathrm{ECT} \%=$ error due to central tendency expressed as a percentage of RMSPE; ER \% = error due to deviation of the regression slope expressed as a percentage of RMSPE; ED\% = error due to the disturbance expressed as percentage of RMSPE; CCC = concordance correlation coefficient; $r=$ correlation coefficient; RSR = RMSPE to standard deviation of observed values ratio. 
Table 7. Evaluation of the performance of $\mathrm{CH}_{4}$ emissions (g/d) prediction models for sheep (ranked by RSR).

\begin{tabular}{|c|c|c|c|c|c|c|c|c|c|c|}
\hline Rank & Model & $\mathrm{n}$ & $\begin{array}{l}\text { RMSPE } \\
(\mathrm{g} / \mathrm{d})\end{array}$ & $\begin{array}{l}\text { RMSPE } \\
\%\end{array}$ & $\begin{array}{l}\text { ECT } \\
\%\end{array}$ & $\begin{array}{l}\text { ER } \\
\%\end{array}$ & $\begin{array}{l}\text { ED } \\
\%\end{array}$ & $\mathrm{CCC}$ & $r$ & RSR \\
\hline 1 & Patra_3 & 90 & 3.33 & 19.2 & 3.45 & 5.31 & 91.2 & 0.75 & 0.81 & 0.61 \\
\hline 2 & IPCC_1997 & 111 & 4.35 & 26.8 & 2.30 & 3.82 & 93.9 & 0.64 & 0.66 & 0.77 \\
\hline 3 & Patra_2 & 111 & 4.41 & 27.2 & 8.69 & 0.00 & 91.3 & 0.59 & 0.66 & 0.78 \\
\hline 4 & Sauvant_1 & 229 & 6.73 & 31.1 & 1.82 & 10.8 & 87.4 & 0.61 & 0.62 & 0.84 \\
\hline 5 & Patra_1 & 274 & 6.71 & 32.7 & 0.64 & 2.18 & 97.2 & 0.51 & 0.55 & 0.85 \\
\hline 6 & IPCC_2006 & 111 & 4.86 & 29.9 & 18.1 & 6.45 & 75.4 & 0.61 & 0.66 & 0.86 \\
\hline
\end{tabular}

Rank = rank of the performance based on the RSR, $n=$ number of observations; RMSPE = Square root of the mean square prediction error,

expressed in g/d and RMSPE\% as a percentage of methane emissions means; ECT\% = error due to central tendency expressed as a percentage of RMSPE; ER\% = error due to deviation of the regression slope expressed as a percentage of RMSPE; ED\% = error due to the disturbance expressed as percentage of RMSPE; $\mathrm{CCC}=$ concordance correlation coefficient; $r=$ correlation coefficient; $\mathrm{RSR}=\mathrm{RMSPE}$ to standard deviation of observed values ratio. 
Table 8. Evaluation of the performance of $\mathrm{CH}_{4}$ emissions ( $\mathrm{g} / \mathrm{d}$ ) prediction models for goats (ranked by RSR).

\begin{tabular}{llccccccccc}
\hline Rank & Model & $\mathrm{n}$ & $\begin{array}{c}\text { RMSPE } \\
(\mathrm{g} / \mathrm{d})\end{array}$ & $\begin{array}{c}\text { RMSPE } \\
\%\end{array}$ & $\begin{array}{c}\text { ECT } \\
\%\end{array}$ & $\begin{array}{c}\text { ER } \\
\%\end{array}$ & $\begin{array}{c}\text { ED } \\
\%\end{array}$ & CCC & $r$ \\
\hline 1 & Patra_4 & 46 & 5.80 & 37.7 & 1.97 & 0.77 & 97.3 & 0.37 & 0.51 & 0.86 \\
2 & Patra_5 & 46 & 6.23 & 40.5 & 7.76 & 1.09 & 91.2 & 0.36 & 0.45 & 0.92 \\
3 & Patra_6 & 46 & 6.59 & 42.8 & 0.45 & 0.03 & 99.5 & 0.06 & 0.16 & 0.98 \\
4 & FAO 2010 & 30 & 10.1 & 65.4 & 48.5 & 5.15 & 46.4 & 0.37 & 0.54 & 1.22 \\
\hline
\end{tabular}

Rank = rank of the performance based on the RSR, $n=$ number of observations; RMSPE = Square root of the mean square prediction error,

expressed in $\mathrm{g} / \mathrm{d}$ and RMSPE\% as a percentage of methane emissions means; ECT\% = error due to central tendency expressed as a percentage of

RMSPE; ER\% = error due to deviation of the regression slope expressed as a percentage of RMSPE; ED\% = error due to the disturbance expressed

as percentage of RMSPE; CCC = concordance correlation coefficient; $r=$ correlation coefficient RSR $=$ RMSPE to standard deviation of observed values ratio. 
Table 9. Evaluation of models using data from individual animals or treatment means.

\begin{tabular}{|c|c|c|c|c|c|c|c|c|c|c|c|}
\hline Validation database & Model type & Model & $\mathrm{n}$ & $\begin{array}{l}\text { RMSPE } \\
(\mathrm{g} / \mathrm{d})\end{array}$ & $\begin{array}{c}\text { RMSPE } \\
\%\end{array}$ & $\begin{array}{c}\mathrm{ECT} \\
\%\end{array}$ & $\begin{array}{c}\text { ER } \\
\%\end{array}$ & $\begin{array}{c}\text { ED } \\
\%\end{array}$ & $\mathrm{CCC}$ & $r$ & RSR \\
\hline \multirow{8}{*}{ Individual } & \multirow{4}{*}{ Individual } & IPCC_1997 & 1797 & 82.3 & 21.2 & 4.10 & 12.8 & 87.1 & 0.68 & 0.68 & 0.79 \\
\hline & & Charmley_2 & 1797 & 84.5 & 21.8 & 7.60 & 9.60 & 82.8 & 0.66 & 0.68 & 0.81 \\
\hline & & Charmley_1 & 1869 & 87.0 & 22.8 & 8.10 & 9.80 & 82.0 & 0.66 & 0.68 & 0.81 \\
\hline & & IPCC_2006 & 1797 & 90.8 & 23.4 & 11.0 & 17.4 & 71.6 & 0.65 & 0.68 & 0.87 \\
\hline & \multirow{4}{*}{ Mean } & Ramin_1 & 463 & 61.0 & 15.6 & 0.71 & 2.92 & 96.4 & 0.75 & 0.76 & 0.66 \\
\hline & & Ramin_2 & 1958 & 82.1 & 21.2 & 6.28 & 3.33 & 90.4 & 0.57 & 0.69 & 0.76 \\
\hline & & Ellis_3 & 1034 & 88.7 & 22.7 & 11.5 & 0.80 & 87.7 & 0.60 & 0.66 & 0.80 \\
\hline & & Sauvant_1 & 967 & 93.5 & 27.4 & 12.5 & 9.90 & 77.6 & 0.63 & 0.66 & 0.85 \\
\hline \multirow{8}{*}{ Means } & \multirow{4}{*}{ Individual } & Charmley_1 & 175 & 64.3 & 16.9 & 6.63 & 22.3 & 9.49 & 0.67 & 0.69 & 0.85 \\
\hline & & Charmley_2 & 171 & 64.3 & 16.9 & 5.10 & 26.6 & 25.8 & 0.68 & 0.69 & 0.87 \\
\hline & & IPCC_1997 & 171 & 65.2 & 17.1 & 3.03 & 30.6 & 21.1 & 0.68 & 0.69 & 0.88 \\
\hline & & IPCC_2006 & 171 & 71.3 & 18.7 & 7.48 & 37.0 & 19.6 & 0.66 & 0.69 & 0.96 \\
\hline & \multirow{4}{*}{ Mean } & Ramin_2 & 178 & 58.3 & 15.2 & 13.4 & 1.46 & 85.2 & 0.62 & 0.72 & 0.77 \\
\hline & & Ramin_1 & 49 & 49.8 & 13.7 & 0.05 & 17.9 & 82.0 & 0.69 & 0.69 & 0.79 \\
\hline & & Sauvant_1 & 81 & 70.9 & 20.2 & 6.66 & 24.2 & 69.1 & 0.62 & 0.64 & 0.92 \\
\hline & & Ellis_3 & 117 & 74.1 & 19.3 & 29.5 & 1.50 & 69.0 & 0.54 & 0.64 & 0.92 \\
\hline
\end{tabular}

$\mathrm{n}=$ number of observations; RMSPE $=$ Square root of the mean square prediction error, expressed in $\mathrm{g} / \mathrm{d}$ and RMSPE\% as a percentage of methane emissions means; ECT\% = error due to central tendency expressed as a percentage of RMSPE; ER\% = error due to deviation of the regression slope expressed as a percentage of RMSPE; ED\% = error due to the disturbance expressed as percentage of RMSPE; CCC $=$ concordance correlation coefficient; $r$ = correlation coefficient; RSR = RMSPE to standard deviation of observed values ratio. 

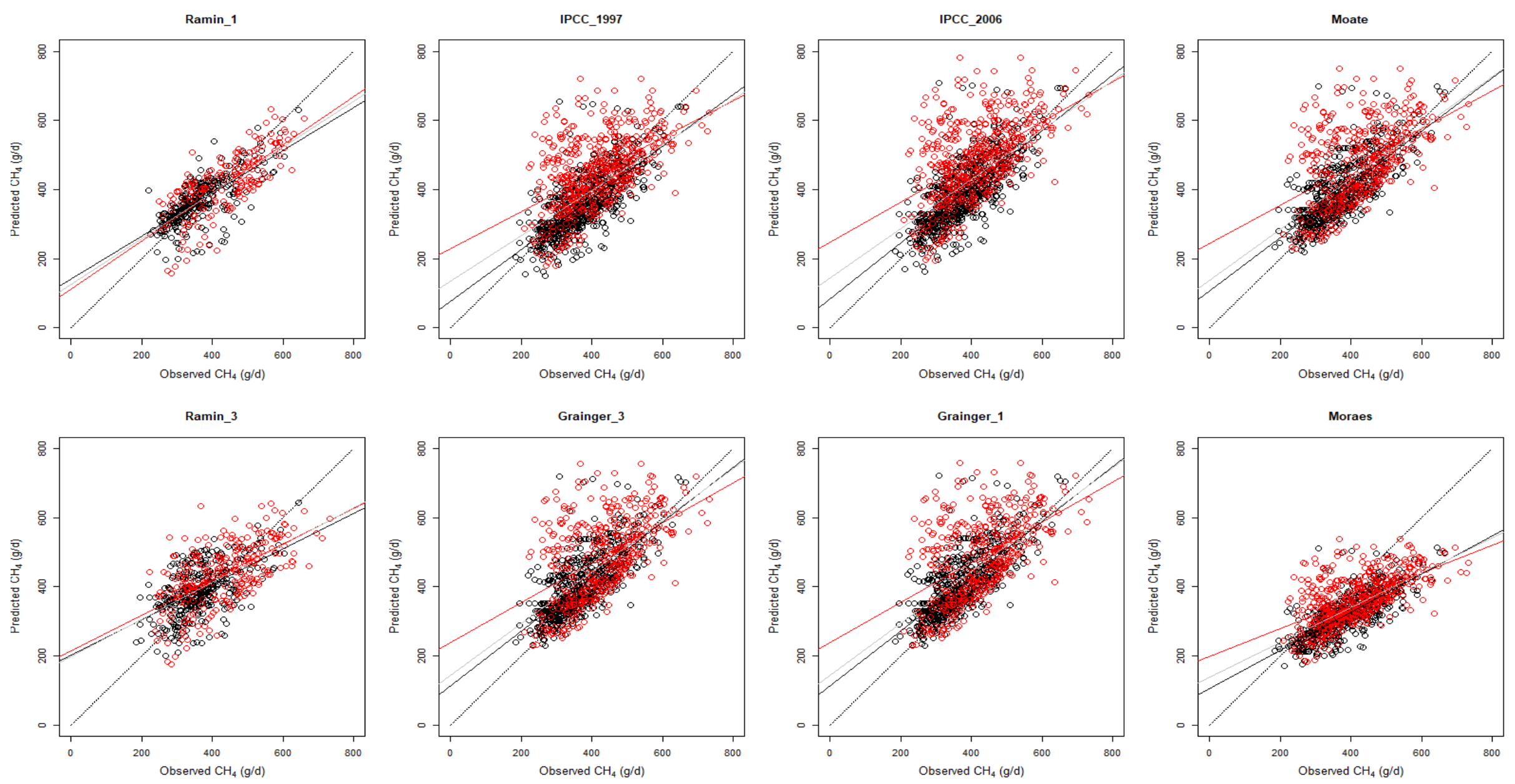

Figure 1. Observed vs. predicted values plots, using dairy cattle data, of 8 models with the smallest RSR for the low- (black points) and the highEE (red points) diets. The black discontinued line is the identity line $y=x$, the gray, black and red lines are the fitted regression lines for all diets, the low- and the high-EE diets, respectively. 

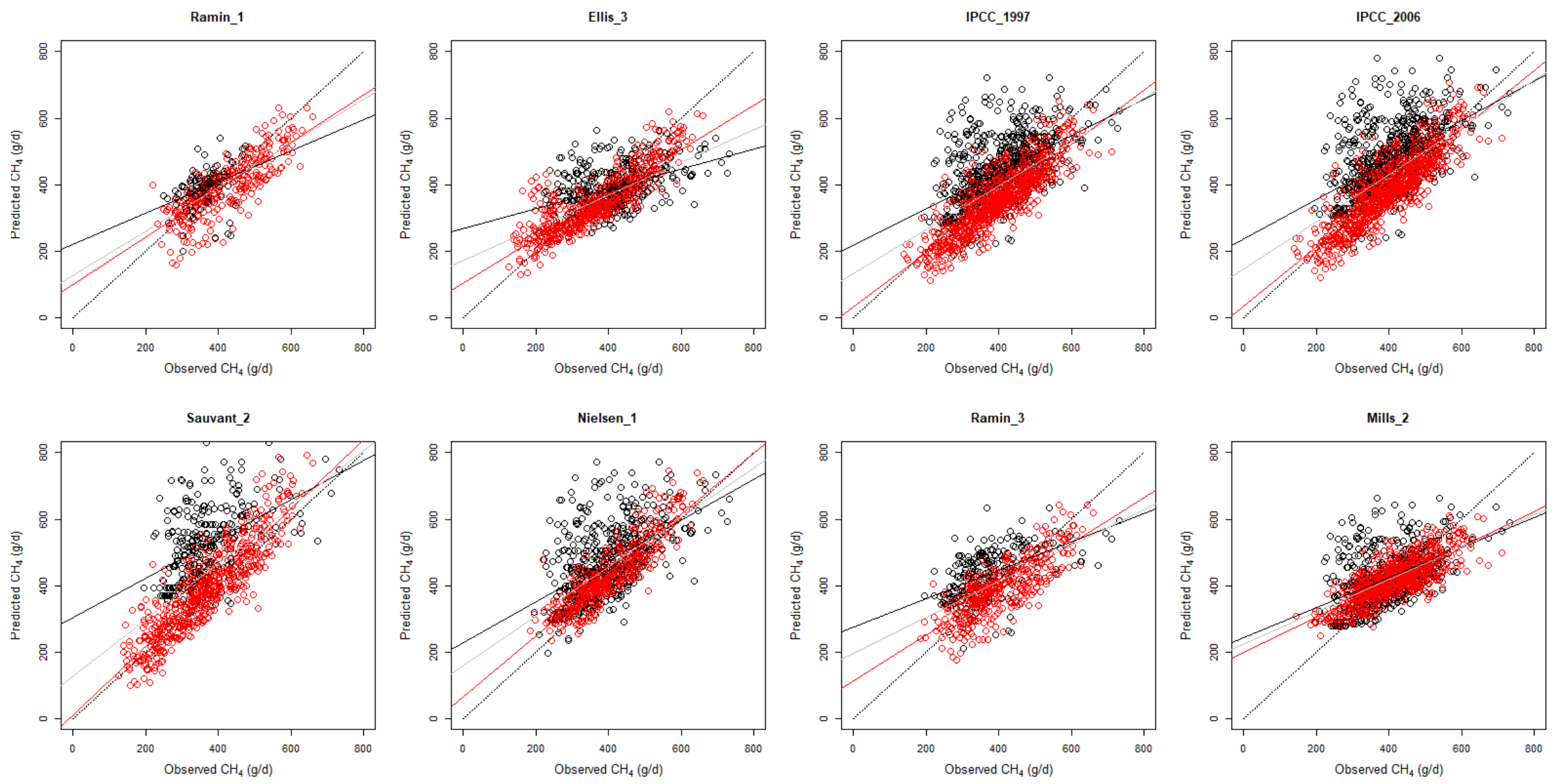

Figure 2. Observed vs. predicted values plots, using dairy cattle data, of 8 models with the smallest RSR for the low- (black points) and the high-

NDF (red points) diets. The black discontinued line is the identity line $y=x$, the gray, black and red lines are the fitted regression lines for all diets, the low- and the high-NDF diets, respectively. 

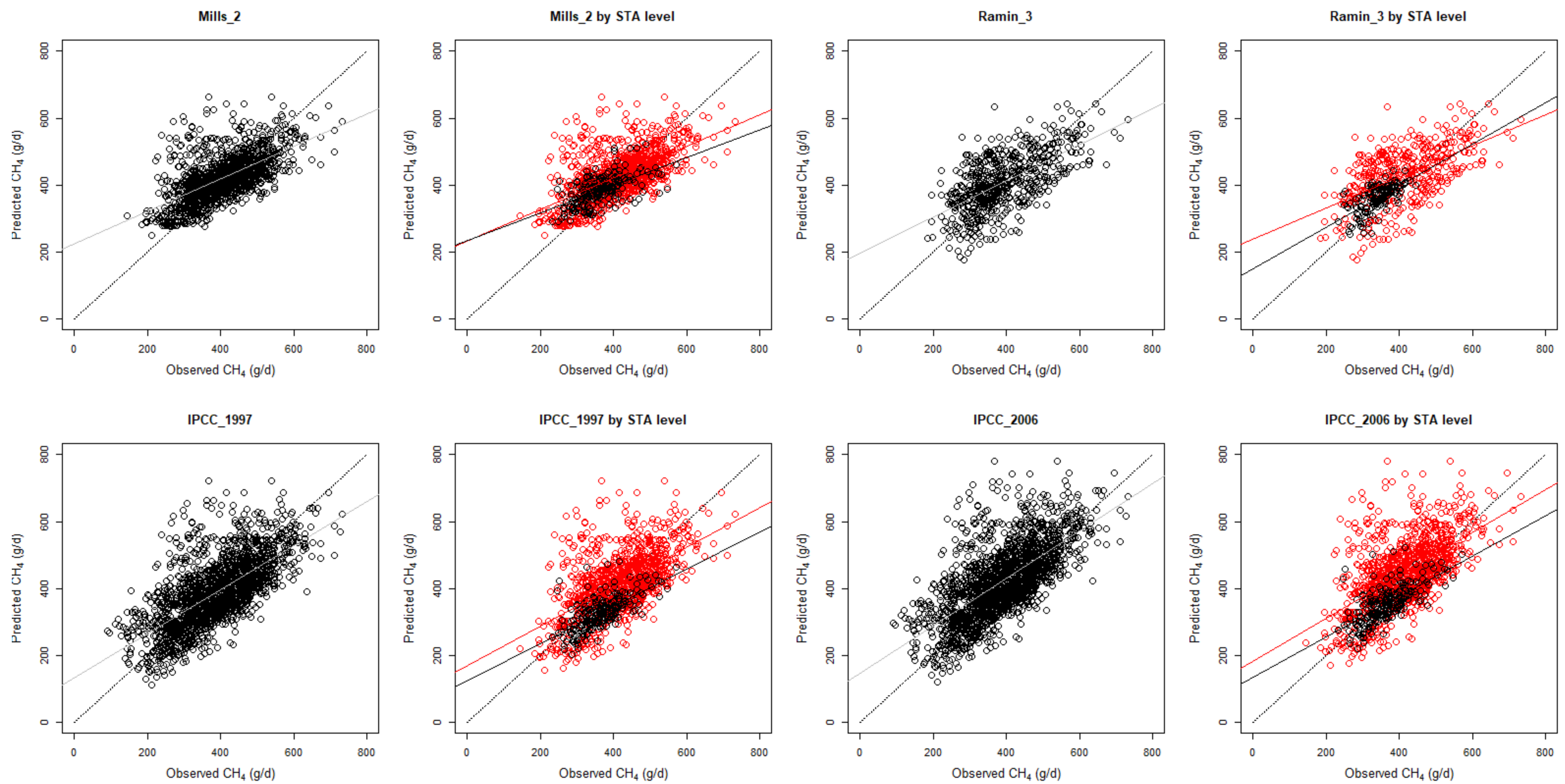

Figure 3. Observed vs. predicted values plots, using all dairy cattle data and for the low- (black points) and the high-STA (red points) diets, of the 4 models Mills_2, Ramin_3, and of IPCC_1997 and 2006. The black discontinued line is the identity line $y=x$, the gray, black and red lines are the fitted regression lines for all diets, the low- and the high-STA diets, respectively. 
Ellis 3

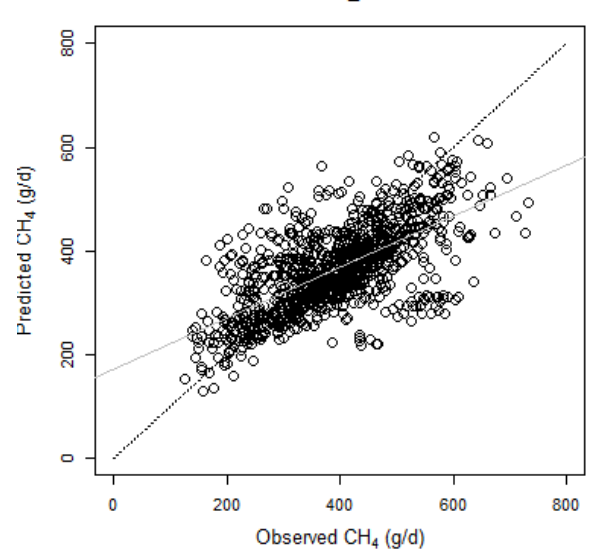

Ellis_2

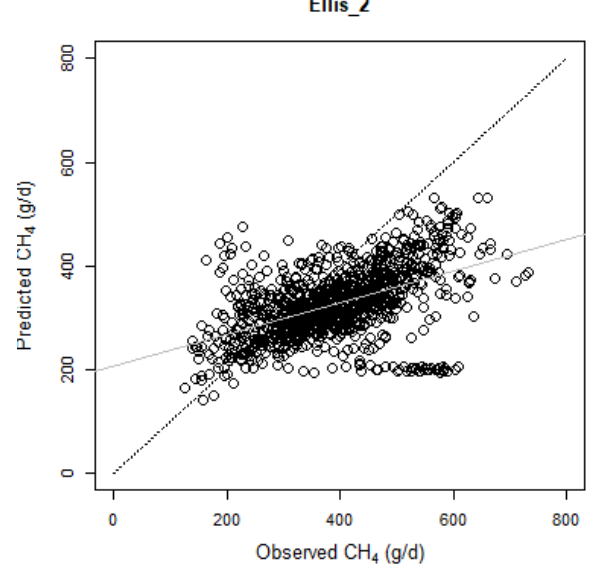

Ellis_3 by dOM

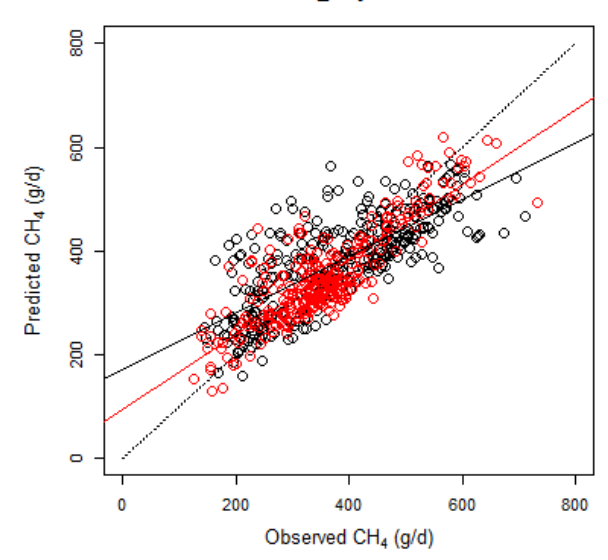

Ellis_2 2 by dOM

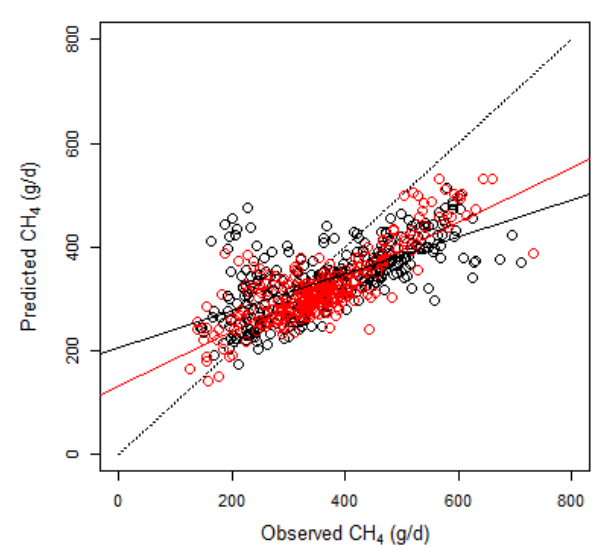

Ramin_1

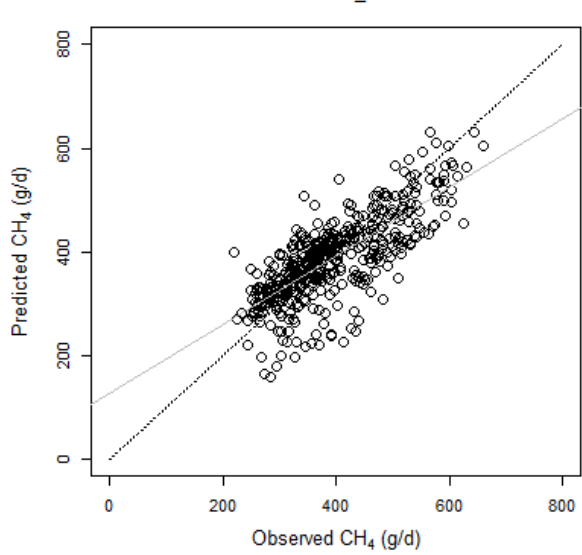

IPCC_1997

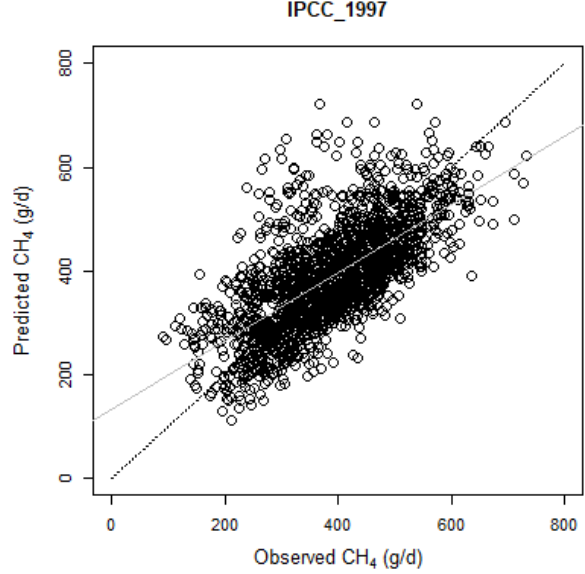

Ramin_ 1 by dOM

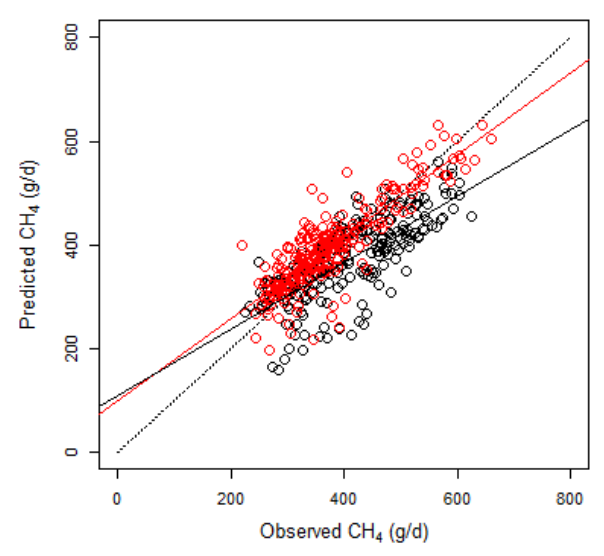

IPCC_1997 by dOM

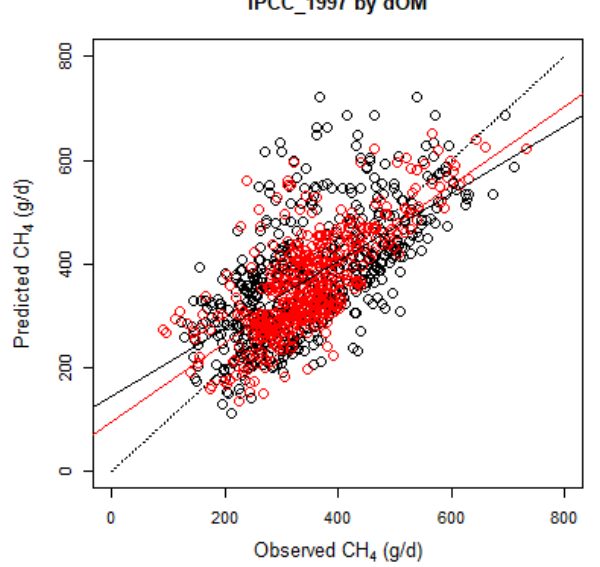

Figure 4. Observed vs. predicted values plots, using all dairy cattle data and for the low- (black points) and the high-dMO (red points), of the 4 models Ellis_3, Ramin_1, and of IPCC_1997 and 2006. The black discontinued line is the identity line $y=x$, the gray, black and red lines are the fitted regression lines for all diets, the low- and the high-dOM diets, respectively. 
Ellis 3

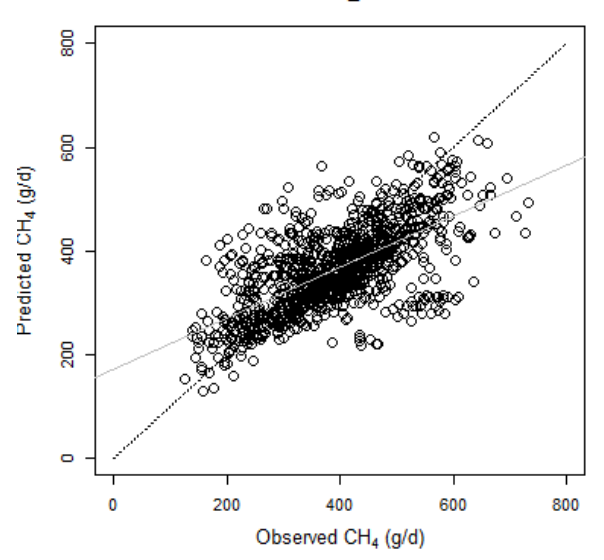

IPCC_1997

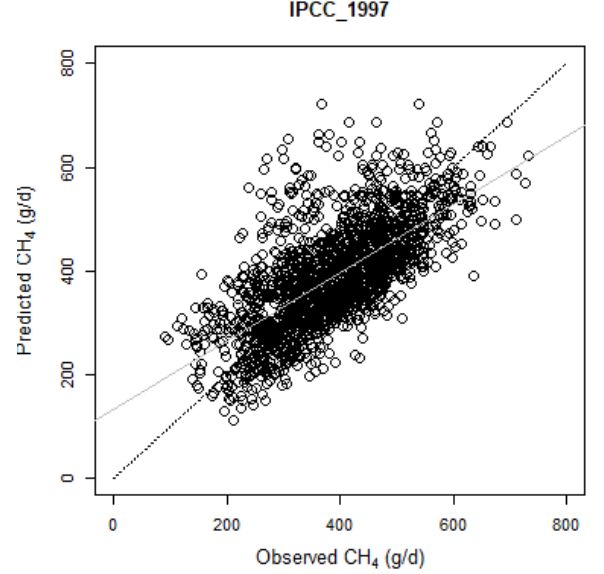

Ellis_3 by dNDF

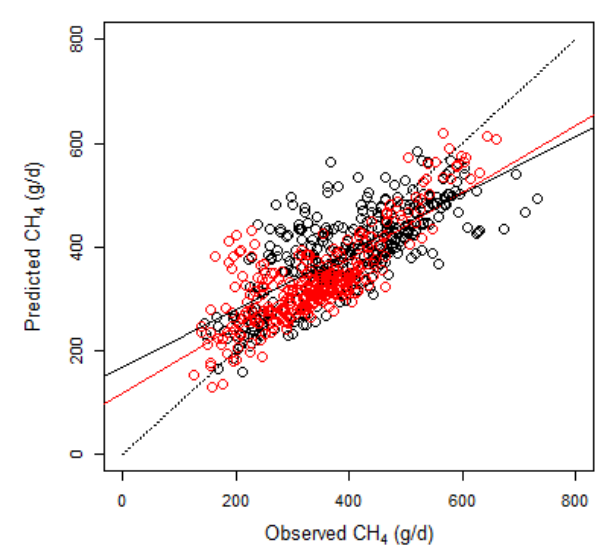

IPCC_1997 by dNDF

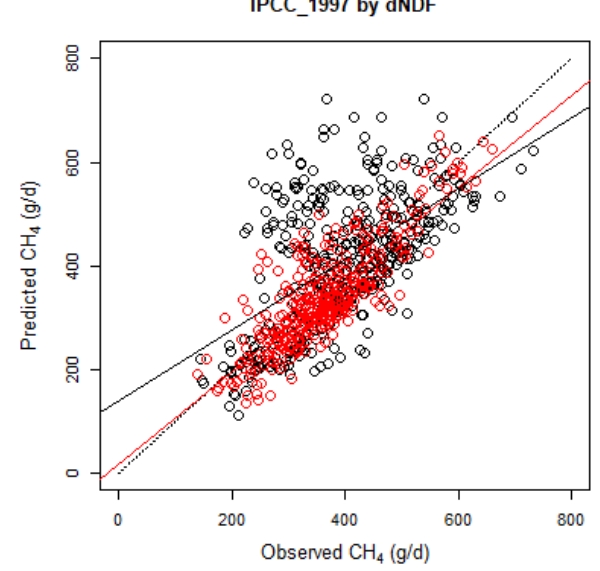

Ramin_3

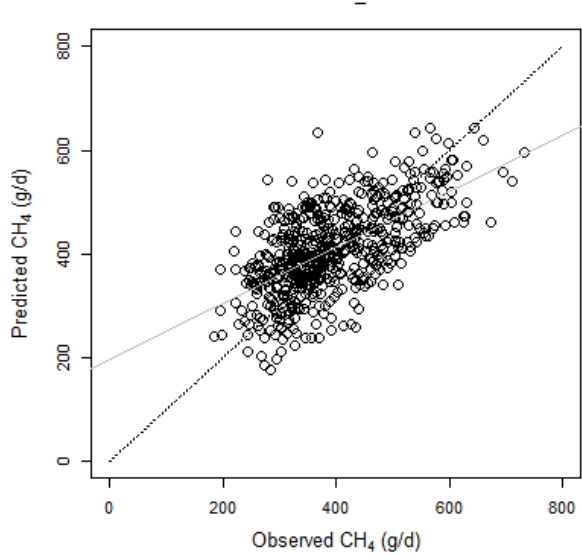

IPCC_2006

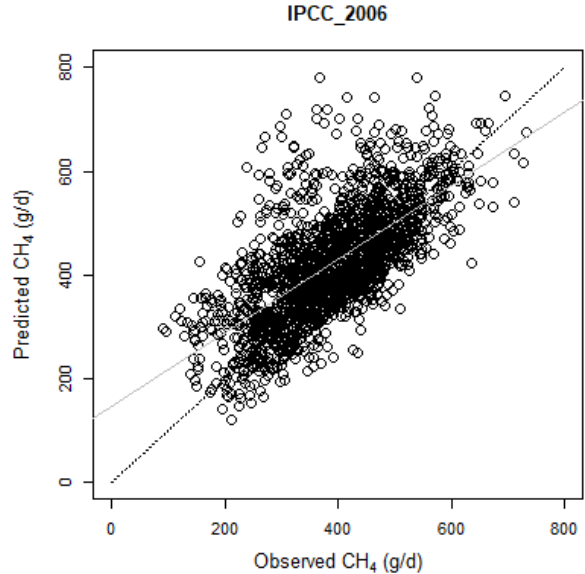

Ramin_ 3 by dNDF

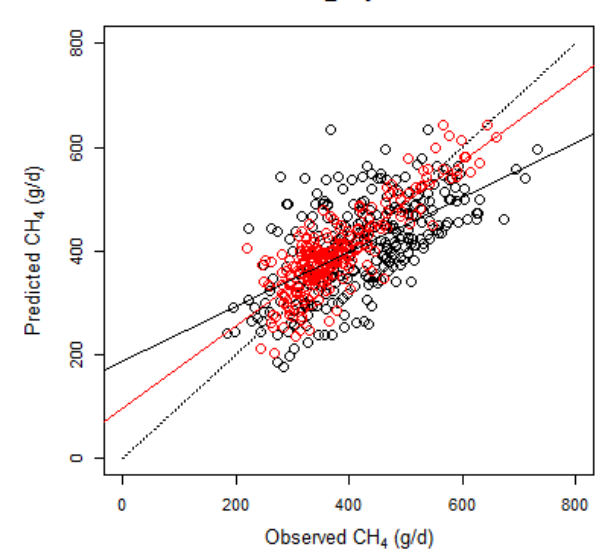

IPCC_2006 by dNDF

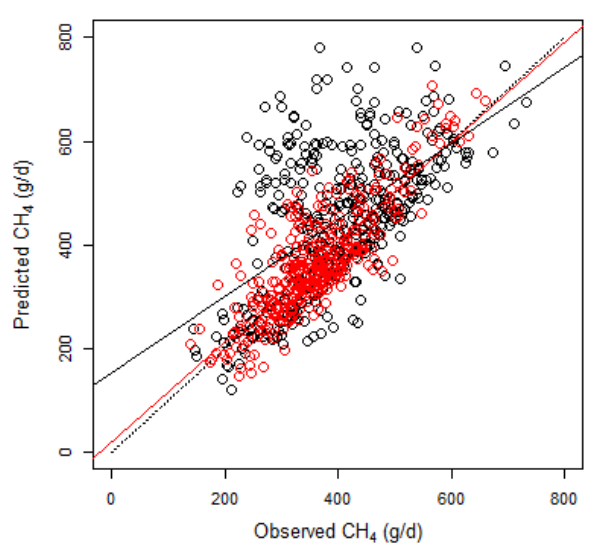

Figure 5. Observed vs. predicted values plots, using all dairy cattle data and for the low- (black points) and the high-dNDF (red points), of the 4 models Ellis_3, Ramin_3, and of IPCC_1997 and 2006. The black discontinued line is the identity line $y=x$, the gray, black and red lines are the fitted regression lines for all diets, the low- and the high-dNDF diets, respectively. 


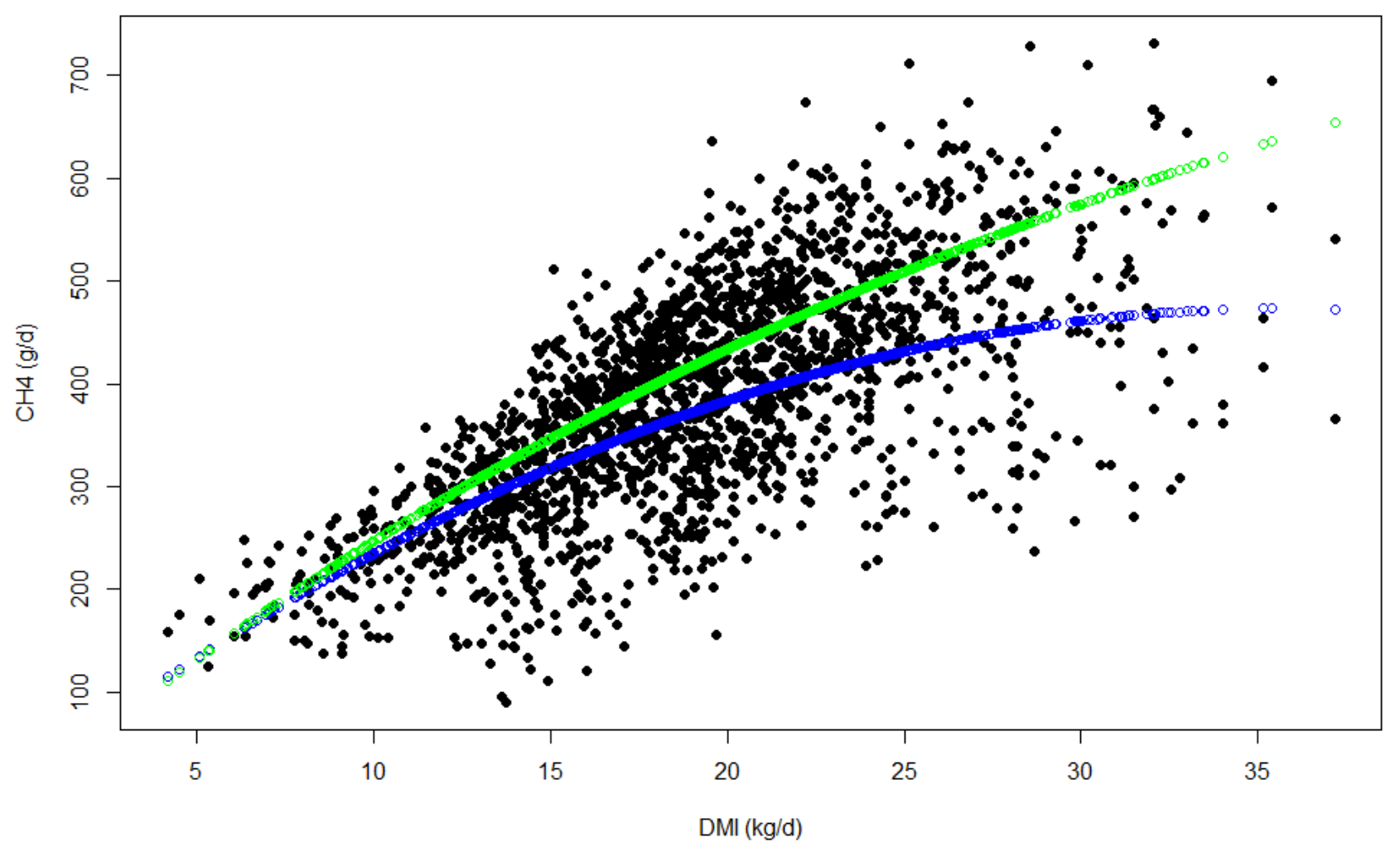

Figure 6. Relationship between DMI (kg/d) and $\mathrm{CH}_{4}$ emissions (g/d) by dairy cattle in our database. The blue and green lines are two DMI-based models evaluated: Ramin_2 $\left[\mathrm{CH}_{4}(\mathrm{~g} / \mathrm{d})=\left(20+35.8 \times \mathrm{DMI}-0.5 \times \mathrm{DMI}^{2}\right) \times 0.714\right]$ and Mills_3 $\left[\mathrm{CH}_{4}(\mathrm{~g} / \mathrm{d})=\left(56.27 \times\left(1-\exp ^{(-0.028 \times \mathrm{DMI})}\right) / 0.05565\right]\right.$, respectively. 